\title{
Anticipatory Anxiety Disrupts Neural Valuation during Risky Choice
}

\author{
기 Jan B. Engelmann, ${ }^{1,2 *}$ Friederike Meyer, ${ }^{1 \star}$ Ernst Fehr, ${ }^{1} \dagger$ and ${ }^{\circledR C}$ Christian C. Ruff ${ }^{1} \uparrow$ \\ ${ }^{1}$ Laboratory for Social and Neural Systems Research (SNS-Lab), Department of Economics, University of Zurich, CH-8006 Zurich, Switzerland, and \\ ${ }^{2}$ Donders Institute for Brain, Cognition and Behaviour, Centre for Cognitive Neuroimaging, Radboud University, 6525 HP, Nijmegen, The Netherlands
}

Incidental negative emotions unrelated to the current task, such as background anxiety, can strongly influence decisions. This is most evident in psychiatric disorders associated with generalized emotional disturbances. However, the neural mechanisms by which incidental emotions may affect choices remain poorly understood. Here we study the effects of incidental anxiety on human risky decision making, focusing on both behavioral preferences and their underlying neural processes. Although observable choices remained stable across affective contexts with high and low incidental anxiety, we found a clear change in neural valuation signals: during high incidental anxiety, activity in ventromedial prefrontal cortex and ventral striatum showed a marked reduction in (1) neural coding of the expected subjective value (ESV) of risky options, (2) prediction of observed choices, (3) functional coupling with other areas of the valuation system, and (4) baseline activity. At the same time, activity in the anterior insula showed an increase in coding the negative ESV of risky lotteries, and this neural activity predicted whether the risky lotteries would be rejected. This pattern of results suggests that incidental anxiety can shift the focus of neural valuation from possible positive consequences to anticipated negative consequences of choice options. Moreover, our findings show that these changes in neural value coding can occur in the absence of changes in overt behavior. This suggest a possible pathway by which background anxiety may lead to the development of chronic reward desensitization and a maladaptive focus on negative cognitions, as prevalent in affective and anxiety disorders.

Key words: decision making; emotion; fMRI; neuroeconomics

\section{Introduction}

Behavior is strongly guided by integral emotions that provide affective information about which behavioral options should be pursued or avoided (Rick and Loewenstein, 2008). How such goal-directed valuation of choice options is instantiated in the human brain is increasingly understood (Rangel et al., 2008; Lee et al., 2012; Levallois et al., 2012; Rushworth et al., 2012), and it is commonly assumed that dysfunctions of these goal-directed neural valuation processes may account for behavioral pathologies in psychiatric diseases (Sharp et al., 2012). However, emotions can also guide behavior more indirectly, for instance, when incidental background emotions (e.g., general or dispositional anxiety) in-

Received July 14, 2014; revised Dec. 19, 2014; accepted Jan. 6, 2015.

Author contributions: J.B.E., F.M., E.F., and C.C.R. designed research; J.B.E. and F.M. performed research; J.B.E. and F.M. analyzed data; J.B.E., F.M., E.F., and C.C.R. wrote the paper.

This work was supported by grants from the Swiss National Science Foundation (CRSIII_141965 and 51NF40_144609) to C.C.R. and E.F. as well as the Swiss National Science Foundation National Center of Competence in Research Affective Sciences. J.B.E. was supported by the Radboud Excellence Initiative, a joint initiative of Radboud University and Radboud University Medical Center. We thank Tony Williams, Yosuke Morishima, and Thomas Epper for helpful comments on the statistical analyses and the manuscript. All authors gratefully acknowledge support from the Neuroscience Center Zurich (ZNZ).

* J.B.E. and F.M. shared first authorship.

†E.F. and C.C.R. shared last authorship.

The authors declare no competing financial interests.

Correspondence should be addressed to either Christian C. Ruff or Friederike Meyer, Laboratory for Social and Neural Systems Research (SNS-Lab), Department of Economics, Blümlisalpstrasse 10, CH-8006 Zürich, Switzerland. E-mail: christian.ruff@econ.uzh.ch or frimey@gmail.com.

DOI:10.1523/JNEUROSCI.2880-14.2015

Copyright $\odot 2015$ the authors $\quad 0270-6474 / 15 / 353085-15 \$ 15.00 / 0$ fluence decisions despite not being relevant for the task at hand. Such effects of incidental emotions on decision making can be strongly detrimental, as evident in psychiatric disorders such as anxiety disorders (Maner et al., 2007; Giorgetta et al., 2012; Grecucci et al., 2013), depression (Harlé et al., 2010; Engelmann et al., 2013), or mania (Minassian et al., 2004). Despite their obvious importance, not much is known about the neural mechanisms by which incidental emotions such as anxiety can affect behavioral choices (Knutson et al., 2008; Harlé et al., 2012).

The lack of knowledge about neural mechanisms for interactions of incidental emotions and choices appears somewhat surprising, given the substantial overlap in the neural circuits involved in decision making and the processing of affective states. For instance, most core structures of the putative valuation network of the brain, encompassing the ventromedial prefrontal cortex (VMPFC), ventral striatum (VS), insula, and amygdala (Hsu et al., 2005; De Martino et al., 2006; Preuschoff et al., 2008; Levy and Glimcher, 2012), are also substantially involved in processing anxiety (Hartley and Phelps, 2012). It is therefore likely that incidental affective and task-related signals computed in these same areas may interact, thereby providing a neural substrate for immediate influences of background emotions on neural valuation during choice. Moreover, persisting incidental affective states may shape processing in these neural structures via neural plasticity, thereby possibly leading to chronic influences on neural computations involved in value-based choice (Paulus and Yu, 2012; Huys et al., 2013). 
Here, we investigate with behavioral, electrophysiological, and neural data how experimentally induced anticipatory anxiety impacts on risky decision making. We chose to induce anticipatory anxiety with a threat-of-shock technique (Schmitz and Grillon, 2012) that has been successfully used in previous studies (Robinson et al., 2011). In this approach, anticipatory anxiety is induced as a physiological and affective response to an ongoing threat of painful stimulation that is temporally unpredictable and incidental to the task (Robinson et al., 2013b). Using this paradigm during fMRI and electrophysiological recording, we thus manipulated our participants' affective state while they completed a set of risky choices involving monetary gains and losses. This allowed us to investigate on a trial-by-trial basis the effects of anticipatory anxiety on individual decision making and underlying neural activity. Importantly, due to our within-subject design, we could adequately control for potentially confounding variables known to influence risk attitude, such as sociodemographic, trait, and genetic factors (Dreher et al., 2009; Capra et al., 2013).

We find that incidental anxiety can fundamentally change the mechanisms of value coding during risky choice in the absence of overt behavioral changes. During anticipatory anxiety, neural coding of subjective value in VMPFC and VS was decreased, but neural coding of negative subjective value in anterior insula was increased, thereby suggesting a shift in value coding from predicted positive consequences toward a focus on possible negative outcomes. This change in neural value coding was clearly linked to observed behavior, as choices during safe trials could be predicted from BOLD signals in the VMPFC and VS (but not in the insula), whereas choices under threat could be predicted from the insula (but not from the VMPFC and VS).

\section{Materials and Methods}

\section{Subjects}

Forty-three right-handed male subjects [mean (SEM) age, 22.56 years (1.42 years)] without a history of psychiatric or neurologic disorder participated in the study. In total, 10 subjects had to be excluded from the study due to technical and image acquisition problems (excessive head movement, $n=1$; scanner crash, $n=3$; sequence problem, $n=1$ ) or noncompliance with the task ( $n=5$; estimation of behavioral models did not converge due to choice patterns that showed too little consistency, which is a common observation (Sokol-Hessner et al., 2009)). This left a total of 33 subjects who were included in all subsequent analyses. Written informed consent was obtained from all subjects, and all procedures were approved by the ethics committee of the canton of Zurich, Switzerland.

\section{Experimental timeline}

Approximately 1 week before the experiment, participants were invited to the laboratory for an "endowment" session in which they were paid for completing a psychological questionnaire battery chosen to assess a comprehensive range of personality characteristics. This battery comprised the DOSPERT scale (Domain-Specific Risk-Taking scale; Weber et al., $2002)$ to assess domain-specific risk attitude, the BIS-11 (Barratt Impulsiveness Scale-11; Patton et al., 1995) to assess impulsivity, the NEO-FFI (NEO-Five Factor Inventory; Borkenau and Ostendorf, 1993) to measure personality characteristics, the STAI (State-Trait Anxiety Inventory; Spielberger et al., 1983) to assess anxiety symptoms, and the BDI (Beck Depression Inventory; Hautzinger et al., 1995) to measure depressive symptom severity. The participation fee for this session was a credit voucher for 50 Swiss francs (CHF; approximately $\$ 58$ US at the time of testing). Importantly, it was stressed to the subjects that the money earned during the endowment session would be their starting balance for the economic games played out in the second session, to avoid excessive risk taking in that session due to the well-documented house money effect (Thaler and Johnson, 1990).

During the second session, fMRI and electrodermal activity were recorded during a risky decision-making task (see Decision-making task section). The task was preceded by a short training session and an individual stimulation thresholding procedure (see Emotion induction technique section). The whole session lasted a total of $120 \mathrm{~min}$ (including subject preparation, scanning time, and postexperimental debriefing) and was remunerated with an additional show-up fee of $50 \mathrm{CHF}$.

\section{Experimental procedures and task}

Emotion induction technique. Anticipatory anxiety was induced by giving participants advance information about impending but temporally unpredictable electric stimulation in two distinct contexts. In the threatening context ("threat trials" triggering anticipatory anxiety), the stimulation was painful, whereas in the matched safe context ("safe trials"), the stimulation was just noticeable but not painful. To this end, we administered electrical stimulation with two DS5 Isolated Bipolar Constant Current Stimulators (Digitimer Ltd.) and custom-made fMRIcompatible $5 \mathrm{~mm}$ ring electrodes. Two of these electrodes were positioned above the first and fourth dorsal interossei muscles of the left dorsal hand, respectively, to provide two separate locations for strong and weak stimulation intensities. This was implemented to avoid desensitization or carryover effects between both contexts. The intensities used for stimulation were individually calibrated before the scanning session with a well-established procedure (Singer et al., 2004). For this purpose, electrical pulses of different intensities were repeatedly administered in a randomized order, and participants rated each pulse on a visual analog scale ranging from 0 (not painful at all/hardly perceptible) to 10 (unbearably painful) in steps of 1 point. Stimulus intensities corresponding to an individual rating of 1 and 8 were chosen for the weak versus strong experimental treatments, respectively. To control for sensitization or desensitization, subjects had to rerate both low- and high-stimulation intensity after each fMRI run, and stimulus intensity was set for each run to the rerated values of 1 and 8 , respectively.

During each fMRI run, stimulation could occur at unpredictable time points during decision-making periods, thus creating threat or safe periods during which participants were expecting strong versus weak electrical stimulation, respectively. The two affective contexts were presented in a blocked fashion. During each block, participants made four risky decisions, as outlined in detail below. To augment the efficacy of anticipatory anxiety induction, the number and time points of electrical stimulation events throughout both threat and safe blocks were determined to be completely unpredictable for subjects. For this purpose, the number of stimulation events was determined for each block by random draw from a gamma distribution (shape parameter, 1; scale parameter, 1). The exact timing of these stimulation events was then determined at random time points between the offset of the cue display and the onset of the resting screen, as determined by drawing from a uniform distribution with the constraint that successive electrical shocks were separated by at least $0.2 \mathrm{~s}$.

The emotion induction was conducted in a within-subject design. Each subject made decisions in both affective contexts and therefore could serve as his own control. This has significant advantages over a between-subject design, where the effects of affective context could be confounded by individual differences in variables that are known to influence risk attitude, such as sociodemographic, personality, and genetic factors (Dreher et al., 2009; Capra et al., 2013). On the flip side, the within-subject design chosen here comes with the small risk that participants may make their choices based on memory when confronted with a specific lottery for a second time, in a different affective context. This conjecture appears highly unlikely, as subjects would need to remember their choices for 280 trials that were presented in random order. We nevertheless took care to inspect our data for such effects, by conducting regression analyses to test whether reaction times were different for lotteries that were presented for the first or the second time (such differences would be expected if participants responded from memory, which requires less deliberation). No such effects were revealed by these analyses (see Results), suggesting that participants used the same strategies to evaluate the first and second presentation of each lottery.

All visual and tactile stimuli were presented and recorded with Cogent 2000 (http://www.vislab.ucl.ac.uk/cogent.php) implemented in MATLAB (MathWorks). 
a
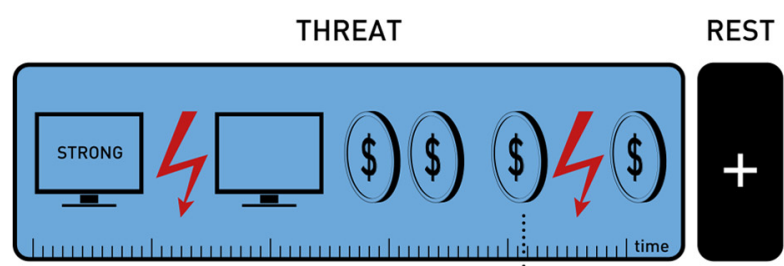

$1.5 \mathrm{~s}$

$2-9 \mathrm{~s}$

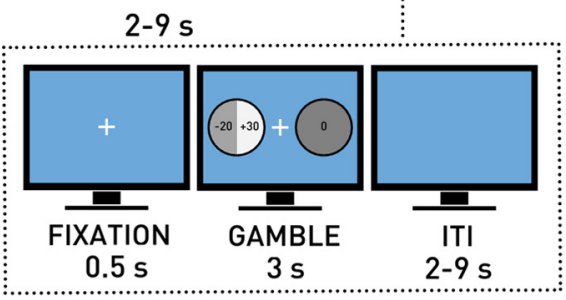

$6 \mathrm{~s}$

$1.5 \mathrm{~s}$
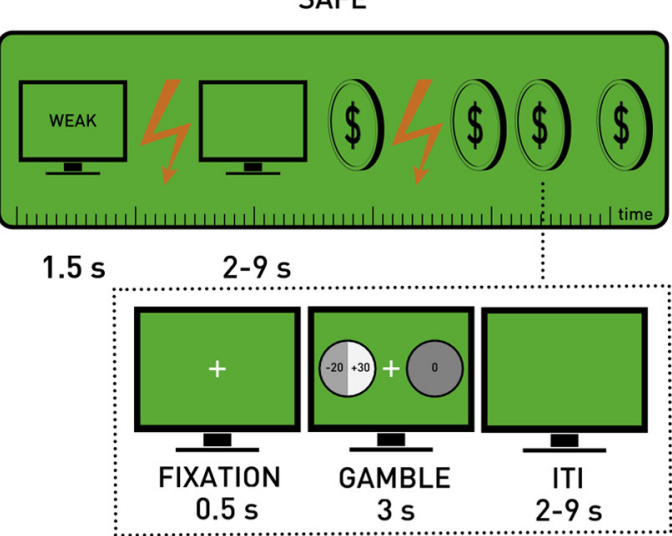

b

20222426283032343638
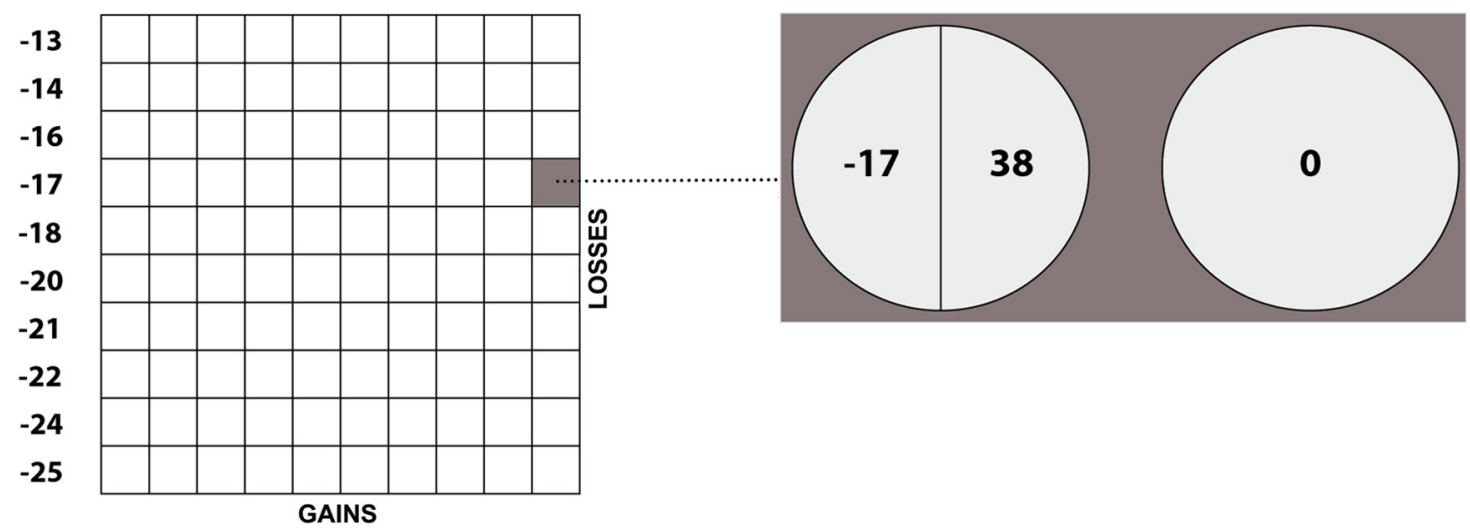

Figure 1. Hybrid fMRI design. $\boldsymbol{a}$, The top row illustrates the timing of different blocks and the bottom row the timing of the gambles. Blocks that were threatening (strong stimulation) or safe (weak stimulation) were randomly interleaved (2 of 10 blocks per run are shown). The type of block was indicated by the screen color (blue or green), which was constant throughout the block. At the beginning of each block, a cue (STRONG or WEAK) was displayed, followed by delivery of a "reminder shock" (dark or light red arrow, respectively, following the cue display). After a jittered intertrial interval (ITI; empty screen), the beginning of a gamble was signaled by a fixation cross, followed by the gamble screen. Subjects were instructed to choose their preferred option (lottery or sure outcome) as fast and accurately as possible via button press. Each block comprised four gambles and was followed by a REST period. Electrical stimulation was delivered randomly and unpredictably during the whole block [indicated by the varying positions of dark red (strong stimulation) or light red (weak stimulation) arrows; the only stimulation-free phases were the rest periods]. $\boldsymbol{b}$, Possible gains and losses for mixed gambles. Gain and loss values were sampled from the gain-loss matrix depicted on the left (columns, gains; rows, losses). Each of the resulting combinations was shown once in the safe and once in the threat condition. For this purpose, the lottery with the corresponding outcomes was shown on one side of the screen, whereas the corresponding safe outcome was shown on the other side (see right panel for the example screen). The presentation sides for lottery option and sure option outcomes were counterbalanced across participants.

Decision-making task. The fMRI experiment consisted of seven runs (each with an average duration of $472 \mathrm{~s}$ ), during which participants made risky decisions in the threat and safe contexts. Each of these runs (Fig. 1a, timeline) comprised five threat blocks with strong stimulation intensity and five safe blocks with weak stimulation intensity. These blocks lasted $43 \mathrm{~s}$ on average and were pseudorandomly interleaved so that not more than two blocks of the same affective valence would follow each other. The single experimental blocks were interleaved with resting blocks of $6 \mathrm{~s}$ duration to allow sustained hemodynamic activity to return to baseline.

During each block, four decision-making trials were presented to the participants. On each trial, participants had to choose between taking part in a lottery with two equiprobable (50/50) options and a sure outcome. In five of the seven functional runs, we used "mixed gambles," in which the lottery led with $50 \%$ probability to a win of amount $x_{1}$ and with $50 \%$ probability to a loss of amount $x_{2}$. The sure outcome was always a zero change in income (Fig. $1 b$, gamble composition). The relationship between gain and loss amounts was chosen to encourage a reasonable amount of risk taking. Previous research indicates that participants overweight losses relative to gains in a multiplicative fashion (Kahneman and Tversky, 1979). We therefore used prospect theory to parameterize gen- eral risk taking and this overweighting (see Behavioral data analysis section) and to inform the analysis of neural valuation processes. All neuroimaging analyses were performed based on the five mixed-gamble runs.

To facilitate parameter estimation for the behavioral choice models, we also included two additional functional runs composed of gain-only and loss-only gambles. These "pure gamble" runs were presented in random positions within the sequence of mixed-gamble runs and included an equal number of gain-only trials (20 trials) and loss-only trials (20 trials) within each run. Pure gambles differed from mixed gambles in that lottery outcomes were now either both positive (50\% probability to win amount $x_{1}$ or $x_{2}$ ) or both negative ( $50 \%$ probability to lose amount $x_{1}$ or $x_{2}$ ). Lottery amounts in the gain-only domain varied between 0 and 30 (in steps of 10) for $x_{1}$, and between 20 and 45 (in steps of 5) for $x_{2}$. Lotteries in the loss-only domain varied between 0 and -30 for $x_{1}$ (in steps of 10), and between -20 and -45 (in steps of 5) for $x_{2}$. The sure outcome was always a nonzero amount generated by calculating a certainty equivalent (CE) corresponding to different levels of risk aversion for each pure lottery. To capture different degrees of risk aversion, five 
different degrees of risk aversion were assumed for both the gain domain and the loss domain; each of these parameter values was used for the calculation of the certainty equivalent for four different lotteries in both the threat and safe context. The CE was calculated as follows:

$$
\begin{aligned}
& \mathrm{CE}_{\text {Gain }}=\left(0.5 x_{1}^{\alpha}+0.5 x_{2}^{\alpha}\right)^{1 / \alpha} \\
& \mathrm{CE}_{\text {Loss }}=\left(0.5 x_{1}^{\beta}+0.5 x_{2}^{\beta}\right)^{1 / \beta},
\end{aligned}
$$

where $\alpha$ and $\beta$ capture the degree of risk aversion in the gain domain and loss domain of the value function, respectively. The following values of $\alpha$ and $\beta$ were used to create CEs: $\alpha=\beta=[0.2,0.5,0.7,0.9,1.3]$ (see detailed description in the Behavioral data analysis section).

Payment schedule. Seven choices were randomly drawn and played out after the experiment (one per functional run). Their mean outcome (which could be negative or positive) was added to the $100 \mathrm{CHF}$ show-up fee for both sessions to determine the participants' final payoff.

fMRI data acquisition. Functional magnetic resonance images were collected using a $3 \mathrm{~T}$ Achieva whole-body magnetic resonance scanner (Philips Medical Systems) equipped with an eight-channel sensitivityencoded (SENSE) head coil (Philips Medical Systems). Structural image acquisition consisted of $180 \mathrm{~T} 1$-weighted transversal images $(0.75 \mathrm{~mm}$ slice thickness). For functional imaging, $\mathrm{T} 2^{\star}$ images were obtained using a SENSE T2*-weighted echoplanar imaging sequence (Pruessmann et al., 1999) with an acceleration factor of 2.0. The sequence consisted of 33 axial slices covering the whole brain (slice thickness, $3 \mathrm{~mm}$; interslice gap, $0.75 \mathrm{~mm}$; ascending sequential acquisition; flip angle, $78^{\circ}$; repetition time, $1750 \mathrm{~ms}$; echo time, $30 \mathrm{~ms}$; field of view, $240 \mathrm{~mm}$; matrix size, $80 \times$ 80 ). To optimize functional sensitivity in orbitofrontal cortex and the medial temporal lobes, we used a tilted acquisition in an oblique orientation at $-20^{\circ}$ relative to the anterior commissure-posterior commissure line (Deichmann et al., 2003).

Psychophysiological measures. To confirm the efficacy of the threat-ofshock treatment, we acquired skin conductance responses (SCRs) using a PowerLab 4/25T amplifier with a GSR Amp (ML116) unit and a pair of MR-compatible finger electrodes (MLT117F). The electrodes were attached to the participant's left index and ring fingers using conducting gel and dedicated Velcro. Recordings were performed with Lab Chart 5 software, with the recording range set to $40 \mu \mathrm{S}$ and using initial baseline correction ("subject zeroing") to subtract the participant's absolute level of electrodermal activity from all recordings (devices and software from ADInstruments). Each participant's SCRs were initially smoothed with a running average over 500 samples $(0.5 \mathrm{~s})$ to reduce scanner-induced noise. Data were then resampled from $1 \mathrm{kHz}$ to $1 \mathrm{~Hz}$ and subsequently $z$-transformed. In line with previously established methods (Bach et al., 2009; Choi et al., 2012), we estimated mean SCRs during the decision periods of both affective conditions with multiple linear regression analysis, as implemented in Analysis of Functional NeuroImages (or AFNI) software (Cox, 1996). The statistical model contained a total of six regressors that reflected the onset times of choices under expectancy of strong and weak electrical shocks, cue times indicating the onset of a block, and delivery times of strong and weak electrical shocks. Average responses to each trial type were estimated via deconvolution from event onset to $16 \mathrm{~s}$ after onset using 17 cubic spline basis functions. Baseline drifts of the SCR were modeled with constant linear and quadratic terms included for each run. For these analyses, SCR datasets of two subjects had to be excluded due to acquisition problems.

Behavioral data analysis. Behavioral data were analyzed using R (www. r-project.org) and Stata (StataCorp). As a first step, reaction times (RTs) and gambling rates (percentage of trials where lotteries were chosen) were compared between the threat and safe contexts. Moreover, we inspected the data for adaptation and order effects by means of a regression model (with robust SEs clustered by subject). This model regressed trial-wise reaction times on variables representing the presentation order of each choice (first vs second presentation in the experiment), affective context (threat vs safe), gain and loss amount, the experimental trial (1-280, to account for learning effects), and all two-way interactions of these variables.

In a second step, Cumulative Prospect Theory (CPT; Bruhin et al., 2010) was used to derive subject-specific prospective utilities $U(x)$ of each lottery $x$ with outcomes $x_{1}$ and $x_{2}$. The lottery in each trial was formalized as follows:

$$
x=\left(x_{1}, p_{1} ; x_{2}, p_{2}\right),
$$

where $p_{i}$ is the probability of obtaining outcome $x_{i}, i \epsilon\{1,2\}$, and $p_{1}+p_{2}=$ 1. To calculate subject-specific values of the lottery, we fitted the value function of prospect theory to determine the value $v\left(x_{i}\right)$ for each outcome $x_{i}$, as follows:

$$
v\left(x_{i}\right)=\left\{\begin{array}{cc}
x_{i}^{\alpha} & \text { if } x_{i} \geq 0 \\
-\lambda\left(-x_{i}\right)^{\beta} & \text { if } x_{i}<0
\end{array}\right.
$$

where $\alpha$ quantifies risk aversion in the win domain, $\beta$ quantifies risk aversion in the loss domain, and $\lambda$ quantifies the overweighting of losses relative to gains. We allowed risk preferences to vary between the threat and safe conditions by defining the following:

$$
\begin{aligned}
& \alpha=(1-T) \times \alpha_{S}+T \times \alpha_{T}, \\
& \beta=(1-T) \times \beta_{S}+T \times \beta_{T},
\end{aligned}
$$

and

$$
\lambda=(1-T) \times \lambda_{S}+T \times \lambda_{T}
$$

where

$$
T= \begin{cases}1 & \text { if threat trial } \\ 0 & \text { if safe trial }\end{cases}
$$

and subscript $S$ denotes parameters for safe trials, whereas subscript $T$ denotes parameters during threat trials. The prospective utility of a gamble, $U(x)$, is defined as follows:

$$
U(x)=\left[p_{1} \times v\left(x_{1}\right)\right]+\left[p_{2} \times v\left(x_{2}\right)\right],
$$

where we ignore the nonlinear probability weighting typically present in prospect theory models because we restricted $p_{1}=p_{2}=0.5$.

To determine the probability $p$ of choosing the lottery option (LO) over the sure option (SO), we used a form of the logit probabilistic choice rule that allows for noise in option selection via the free parameter $\mu$, as follows:

$$
p(\mathrm{LO}, \mathrm{SO})=1 /\left[1+\left(e^{-\mu(\mathrm{U}(\mathrm{LO})-\mathrm{U}(\mathrm{SO}))}\right)\right] .
$$

fMRI data analysis. Preprocessing and statistical analyses of functional data were performed using SPM8 (Wellcome Department of Imaging Neuroscience, London, UK). All functional volumes were realigned to the first volume using b-spline interpolation and were unwarped using fieldmaps estimated by SPM to remove residual movement-related variance due to susceptibility-by-movement interactions (Andersson et al., 2001). To improve coregistration, bias-corrected and coregistered anatomical and mean echoplanar images were created using the New Segment toolbox in SPM. The forward deformation fields created in the context of the nonlinear normalization of individual gray matter tissue probability maps were then used to normalize the functional time series to the Montreal Neurological Institute (MNI) T1 template. Finally, functional data underwent spatial smoothing using an isotropic $6 \mathrm{~mm}$ FWHM Gaussian kernel.

Statistical analyses were performed using the general linear model (GLM; Friston et al., 1994). Regressors of interest were modeled using canonical hemodynamic response functions (HRFs) temporally aligned with the onset of the events of interest. Time and dispersion derivatives were added to account for subject-to-subject and voxel-to-voxel variation in response peak and dispersion (Henson et al., 2002). Neural processes triggered by lottery presentation per se (averaging over all different lotteries) were modeled with two regressors (trials in safe context, trials in threat context). Neural valuation processes on each trial were modeled with two parametric regressors (one for threat trials and one for safe trials) that coded the neural expected subjective value (ESV) of each lottery (Levy et al., 2010), as was also done in other studies of mixed gambles (Minati et al., 2012a,b; Sokol-Hessner et al., 2013). ESV was 
defined for each gamble as the neural representation of the behaviorally measured $U(x)$ (see Behavioral data analysis section) and was assumed to linearly correlate with $U(x)$ (Levy et al., 2010). As the SO was 0 for all mixed-gamble trials, it was omitted from the GLM. The value regressors in the GLM spanned for each trial the decision period from the onset of the decision screen until the subject's choice, as indicated by button press. Estimation of the behavioral model revealed that the loss aversion coefficients $\lambda_{T}$ and $\lambda_{S}$ were not significantly different from each other. In a similar vein, no significant deviations from 1 were found for the risk aversion parameters $\alpha_{S}, \alpha_{T}, \beta_{S}$, and $\beta_{T}$. We therefore used the individual mean loss aversion coefficient $\lambda=\left(\lambda_{\mathrm{T}}+\lambda_{\mathrm{S}}\right) / 2$ as subject-specific input to derive the predicted neural valuation processes for each trial. Note, however, that inclusion of the estimated loss aversion coefficients in the $T$ and $S$ conditions, $\lambda_{\mathrm{T}}$ and $\lambda_{\mathrm{S}}$, instead of the average of the two conditions, did not lead to significantly different fMRI results. Additional regressors added to the first-level GLM corresponded to the cues at the beginning of the blocks, actual electrical stimulation at weak and strong intensities, and trials where participants omitted responses. The main effects and interactions of affective context and decision making were computed with linear contrasts of the first-level parameter estimates, resulting in one contrast estimate for each of these effects in each participant.

Statistical inference was performed with second-level random-effects comparisons of the first-level contrasts representing the trial onset and ESV regressors for the threat and safe context. We tested our hypotheses about changes in neural valuation due to anticipatory anxiety in regions of interest (ROIs) previously shown to be involved in neural valuation and emotion processing. These regions comprised the VMPFC (Levy and Glimcher, 2011; Winecoff et al., 2013), VS (Tom et al., 2007; Bartra et al., 2013; Robinson et al., 2013a), insula (Robinson et al., 2013a), and amygdala (Jenison et al., 2011; Fossati, 2012). Bilateral masks for amygdala and insula were taken from the WFU PickAtlas (http://fmri. wfubmc.edu/software/PickAtlas). For VMPFC and VS, which are anatomically less distinctively defined, we used MNI coordinates and extent estimations from the published literature. MNI coordinates for the VMPFC mask (right VMPFC: $x=4.27, y=35.18, z=11.82$; left VMPFC: $x=-7.29, y=38, z=-10.57$; spheres with $12 \mathrm{~mm}$ radius) were taken from a meta-analysis of neural valuation processes (Levy and Glimcher, 2012). Bilateral MNI coordinates for the VS [bilateral inferior vs (nucleus accumbens): $x= \pm 9, y=9, z=-8$; superior ventral striatum (ventral caudate): $x= \pm 10, y=15, z=0$; spheres with $6 \mathrm{~mm}$ radius] were taken from a study using connectivity-based parcellation of the striatum (Di Martino et al., 2008), which has also been used for this purpose by other studies (Kelly et al., 2009). These eight regions were combined into a simple ROI mask using the WFU PickAtlas "Union" function. All analyses of value-related responses were restricted to this inclusive mask with the statistical threshold set at $p<0.001$, uncorrected, which is in line with the threshold commonly used in a priori defined hypothesis tests of value-related responses in these regions (Plassmann et al., 2010; Kang et al., 2011; Litt et al., 2011; Lin et al., 2012; Sokol-Hessner et al., 2012). Additionally, we ran exploratory whole-brain analyses with a statistical threshold of $p<0.05$, which was familywise error (FWE) corrected for the full brain.

Trial-by-trial regression analysis of the relationship between ROI signal and subjective value. To confirm the results of the SPM analyses with independent data, we examined the link between subjective values and neural activity in analyses of the trial-by-trial time course data extracted from the VMPFC, VS, and insula. We used the leave-one-subject-out (LOSO) cross-validation procedure (Esterman et al., 2010), in which regions for the extraction of each subject's data are defined by a GLM analysis of value responses in the other $N-1$ subjects. This procedure ensures that ROI analyses are performed on new data that are independent of those used for ROI definition, thereby avoiding circular inference (Kriegeskorte et al., 2009) and allowing within-sample replication in an independent dataset.

Specifically, activation time courses were extracted from spherical volumes of interest (VOIs) centered on the activation foci from each LOSO GLM within the VMPFC (12 $\mathrm{mm}$ radius), VS (6 $\mathrm{mm}$ radius), and insula (12 $\mathrm{mm}$ radius). Data were spatially averaged over the sphere and were temporally downsampled to one value for each trial, by averaging over 4 images within the period of 3.5-10.5 s after trial onset. This ensured that the data summarized the delayed and dispersed hemodynamic response reflecting choice-relevant computations (RTs ranged from 0.48 to $6.16 \mathrm{~s}$ after stimulus onset). Spatial and temporal averaging and correction for session and movement confounds were implemented using the VOI toolbox in SPM8.

As a first step, we examined whether trial-by-trial activity within our regions of interest encodes subjective value differentially during the presence of threat relative to no threat. To this end, we regressed trial-by-trial signal changes in our ROIs on subjective value and threat, and their interaction, using the following model:

$$
\begin{aligned}
\text { Signal }_{\mathrm{ti}}=\beta_{1} * \mathrm{SV}_{\mathrm{ti}}+\beta_{2} * T_{\mathrm{ti}}+\beta_{3} *\left(\mathrm{SV}_{\mathrm{ti}} * T_{\mathrm{ti}}\right) & +\beta_{4} * X_{\mathrm{ti}} \\
& +\mathrm{TR}_{\mathrm{ti}}+\mathrm{e},
\end{aligned}
$$

where for each subject $i$ on trial $t$, Signal is the regional signal within a given ROI, SV reflects the subjective value, $T$ is a dummy variable that encodes the presence of threat, $X$ reflects a vector of subject-specific confounding variables that include age, trait anxiety and the emotional stability subscale of the NEO-FFI, and $\mathrm{TR}_{\mathrm{ti}}$ denotes trial number to control for temporal variation in the signal.

Prediction of choices from activation time courses in VOIs. To demonstrate the link between brain activity in each region of interest and the overt economic choices, we performed prediction analyses of choices based on neural signals (Kuhnen and Knutson, 2005; Berns et al., 2008). These analyses were conducted to investigate whether neural signals from independently defined regions in VMPFC, VS, and insula predict overt choice, and how this predictive relationship changes with affective context (threat vs safe). To this end, we conducted logistic regression of mixedgamble acceptance on neural signals (extracted from subject-specific regions using the identical LOSO approach as described above), affective context (threat, safe), and their interaction using the following model:

$$
\begin{aligned}
\text { Choice }_{\mathrm{ti}}=\beta_{1} * \text { Signal }_{\mathrm{ti}}+\beta_{2} * T_{\mathrm{ti}}+\beta_{3} * \operatorname{Signal}_{\mathrm{ti}} * T & +\beta_{4} * X_{\mathrm{ti}} \\
& +T R_{\mathrm{ti}}+e,
\end{aligned}
$$

where for each subject $i$ on trial $t$, Choice is a dummy variable that reflects the acceptance of mixed gambles, Signal is the regional signal within a given ROI, $T$ is a dummy variable that codes the presence of threat, $X$ reflects a vector of subject-specific confounding variables that include age, trait anxiety and the emotional stability subscale of the NEO-FFI, and $\mathrm{TR}_{\mathrm{ti}}$ denotes trial number to control for temporal variation in the signal.

For both regression models, we first conducted analyses of all trials to test how affective context interacts with subjective values (Eq. 11; ordinary least squares) or regional BOLD signals (Eq. 12; Logit). To further characterize these interactions, we then conducted follow-up analyses of only threat trials and only safe trials, using a simpler model that did not include the affective-context factor and its interaction. The parameters of all regression models were estimated using robust and clustered SEs that correct for heteroscedasticity and correlated responses from each subject using the Huber-White method implemented in the robcov function of the Regression Modeling Strategies (RMS) package in R. Statistical inference on the estimated parameters was performed at a one-tailed $p<0.05$, given the clear hypotheses in these confirmatory analyses.

Psychophysiological interaction analysis. To test whether the induction of anticipatory anxiety caused changes in the functional connectivity within the valuation network (VMPFC, VS, insula, and amygdala) and with regions outside this network, we conducted psychophysiological interaction (PPI) analyses using a generalized form of context-dependent PPI analysis (McLaren et al., 2012). PPI regressors were added to the same statistical model as described above (but omitting parametric modulators). Seed regions for PPI analysis were defined as spheres with a 3 $\mathrm{mm}$ radius centered on peak voxels of activation found in the ESVrelated contrasts of the GLM analysis. To obtain an estimate of neural activity within the seed region, the first temporal eigenvariate of a principle component analysis of the BOLD signal in all voxels of the seed region was extracted and deconvolved (Gitelman et al., 2003). A new GLM was then estimated for each subject that included the original de- 
sign matrix and the following additional regressors: the deconvolved time course from the seed region and two psychological interaction regressors (risky decisions in the threat condition and the safe condition). These regressors were created by multiplying the neural activity in the seed region during the relevant decisions with the regressors corresponding to the decision-related activity in the two contexts (condition-specific onset and offset times convolved with the canonical HRF). PPI contrast maps for each subject were entered into a second-level random-effects group analysis using the same inference procedures as for the GLM analyses described above.

Please note that these PPI analyses were conducted on the residuals of the original GLM model; this ensures that any changes in functional coupling are estimated after the average activity elicited by each decision type has been modeled. Changes in PPI coupling therefore cannot be confounded by changes in overall signal during both conditions. Moreover, to ensure that changes in noise/signal variability during the two affective contexts cannot confound the PPI analyses, we also compared the signal-to-noise ratio (SNR) within the VMPFC, VS, and insula during threat and safe blocks. To this end, we extracted the filtered signal time series from a $12 \mathrm{~mm}$ sphere centered on our activation peaks within the VMPFC and insula and from a $6 \mathrm{~mm}$ peak centered on our activation peak in VS for the time periods corresponding to the threat and safe blocks. We then calculated the SNR (defined as the absolute conditionspecific mean/the condition-specific SD) during safe and threat blocks, and compared them statistically. This did not reveal any SNR differences between safe and threat blocks in $\operatorname{VMPFC}\left(t_{(32)}=0.291, p=0.773\right)$, VS $\left(t_{(32)}=1.182, p=0.246\right)$, and insula $\left(t_{(32)}=0.475, p=0.638\right)$, even after controlling for confounding factors, such as age and trait anxiety (VMPFC: affective context coefficient estimate, $-0.008, T=-0.30, p=$ 0.769; VS: affective context coefficient estimate, $-0.033, T=-1.20, p=$ 0.236; insula: affective context coefficient estimate, $-0.020, T=-0.48$, $p=0.632$ ). This demonstrates that any change in PPI coupling between both affective contexts is not confounded by differences in overall signal or noise levels and therefore most likely reflects changes in functional coupling.

\section{Results}

\section{Threat of shock induces anticipatory anxiety}

Analysis of the SCR, behavioral, and neuroimaging data confirmed that our threat-of-shock manipulation was indeed successful in inducing anticipatory anxiety. First, mean SCRs during decision trials in threat periods were increased relative to those during safe decision trials. A two-way repeated-measures ANOVA (with Greenhouse-Geisser correction) with factors time $(0-16 \mathrm{~s}$ following trial onset, averaged across $1 \mathrm{~s}$ bins) and affective context (threat vs safe) revealed significant main effects for both affective context $\left(F_{(1,30)}=82.180, p<0.0001\right)$ and time $\left(F_{(16,30)}=3.245, p<0.019\right)$, as well as a significant interaction of affective context and time $\left(F_{(1,16)}=31.15, p<0.001\right)$. These SCR increases lasted for the full trial (from 1 until $16 \mathrm{~s}$ after each trial onset), as indicated by Bonferroni-corrected pairwise $t$ tests contrasting SCR responses during threat and safe trials (all $t_{(30)}=$ 9.07, all $p<0.0001$ ). Thus, the ongoing threat of painful shocks had a physiologically arousing impact on our participants during the performance of the choice paradigm.

Second, SCR increases for threat contexts were also evident during time periods when electrical stimulation was actually administered. ANOVA (with Greenhouse-Geisser correction) of the SCR data following stimulus administration also revealed highly significant main effects of affective context $\left(F_{(1,30)}=48.2\right.$, $p<0.0001)$ and time $\left(F_{(16,30)}=15.826, p<0.0001\right)$, as well as a significant interaction of affective context and time $\left(F_{(1,16)}=\right.$ $16.3, p<0.0001)$. These SCR increases for strong relative to weak stimulation were evident from 3 until $16 \mathrm{~s}$ after the onset of the electric stimulus (all $t_{(30)}=6.94$, all $p<0.001$ ). This confirms that the strong stimulation itself- on top of the expectation of this stimulation throughout the block-led to strong physiological arousal in our participants (Fig. 2a).

Third, the arousing impact of the anticipatory anxiety during threat contexts was also confirmed by the choice RT data (Fig. $2 b$ ). A regression of RTs on the independent variables affective context (threat vs safe) and choice (LO and SO) revealed significant effects for both affective context $\left(t_{(32)}=-3.01, p=0.005\right)$ and choice $\left(t_{(32)}=-4.24, p<0.001\right)$, but no interaction $\left(t_{(32)}=\right.$ $-0.11, p=0.91)$. Participants were faster to respond when choosing LO than when choosing SO, and, importantly, also for choices in the threat versus safe context. The latter result demonstrates the effectiveness of our emotional manipulation on overt behavior (Robinson et al., 2013b).

Finally, the affective efficiency of the painful electric stimulation during threat contexts was also confirmed by the fMRI data. When contrasting neural responses to the strong stimulation during threat blocks with those to the weak stimulation in safe blocks, we observed activation of a putative pain matrix (Tracey and Mantyh, 2007; Leknes and Tracey, 2008), including bilateral insula, bilateral supplementary motor area, cerebellum, and right anterior/mid-cingulate cortex $(p<0.05$, whole-brain FEW corrected; Fig. 2c).

\section{Anticipatory anxiety does not affect revealed preferences}

The analysis of the choice data showed that anticipatory anxiety did not change overt preferences, as measured with different indices. First, gambling rates did not differ significantly between threat and safe trials $\left(t_{(32)}=0.05, p=0.96\right.$; Fig. $\left.3 a\right)$. Subjects were in fact highly consistent in their decisions between threat and safe trials. When specific gambles were offered in both contexts, the same option was chosen in $89 \%$ of cases (Fig. 3b). Second, when preferences were modeled via CPT, we found mild degrees of loss aversion that did not differ between the threat and safe contexts (Fig. 3c), as confirmed via $t$ test of the difference between $\lambda_{S}$ and $\lambda_{T}$ [mean (SEM); $\lambda_{S}=1.291(0.05)$ and $\lambda_{T}=1.29(0.05) ;\left(\lambda_{S}-\right.$ $\left.\left.\lambda_{T}\right)=-0.0007(0.0085) ; t_{(32)}=0.08, p=0.93\right]$. Finally, we tested whether the curvature for gains and losses was changed during the threat of shocks compared with the safe contexts. We did not observe any significant differences between both contexts for $\alpha$ $\left[\alpha_{T}=0.933(0.0118) ; \alpha_{S}=0.934(0.0126) ; t_{(32)}=-0.5052, p=\right.$ $0.617]$ and $\beta\left[\beta_{T}=1.077(0.0144) ; \beta_{S}=1.078(0.0134) ; t_{(32)}=\right.$ $0.2189, p=0.8281]$. Across participants, the small changes in loss aversion and risk attitude due to affective context appeared to be normally distributed (as confirmed by the test for normality of Lilliefors, 1967; with $\lambda: D=0.14, p=0.13$; Fig. $3 d$; with $\alpha: D=$ $0.12, p=0.29$; and with $\beta: D=0.12, p=0.27$ ). Thus, any changes in loss aversion and risk attitude due to anticipatory anxiety were not significantly different from zero and were normally distributed across participants; it is therefore unlikely that different participants reacted in a different manner to the affective manipulation.

The similar choice behavior in the two affective contexts raises the question of whether participants may have responded from memory when each lottery was presented for the second time in a different affective context. Such memory effects are generally unlikely, as participants would have to remember their responses across 280 trials, and as the presentation order across affective contexts was fully balanced. Nevertheless, we explicitly tested whether participants pondered their choices in a similar fashion for first and second presentations of lotteries within each context, by means of regression models that included the order of presentation of identical gambles (first vs second presentation), affective context (threat vs safe), the experimental trial (1-280), gain 
a
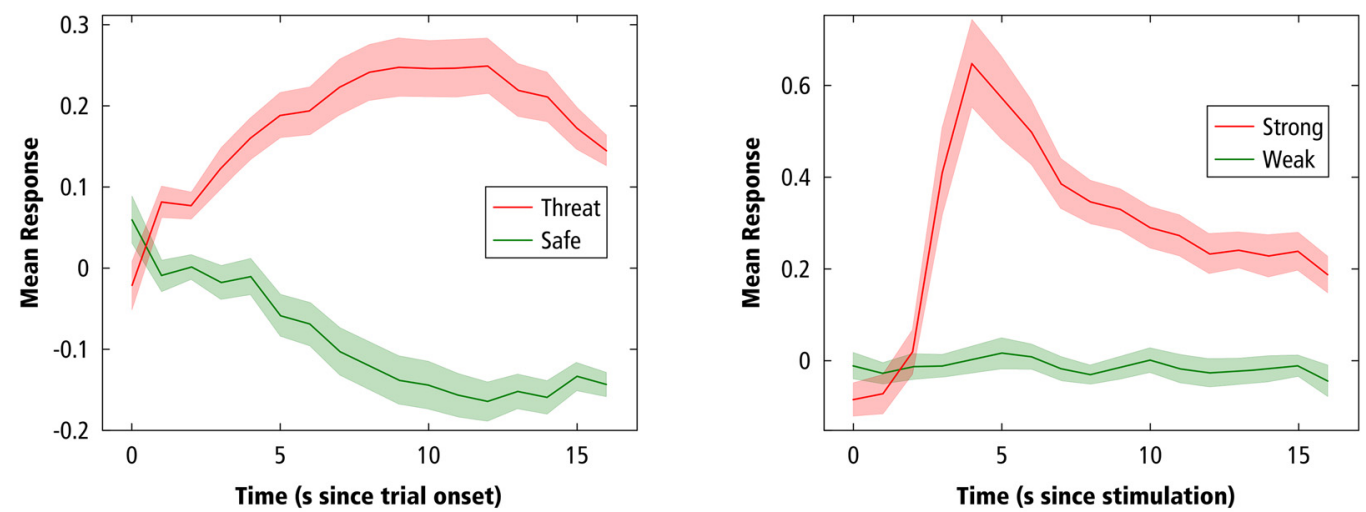

b

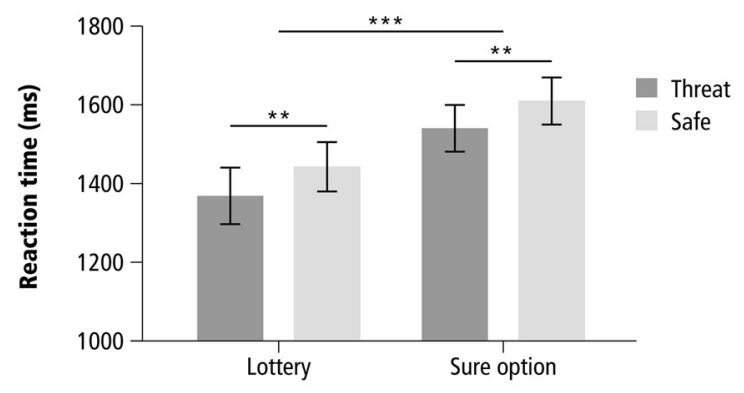

C

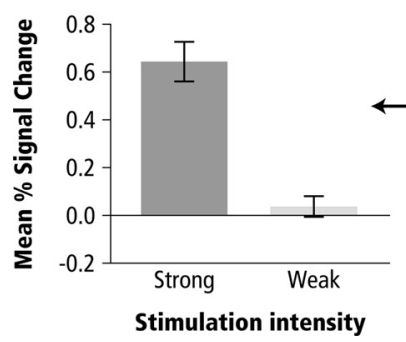

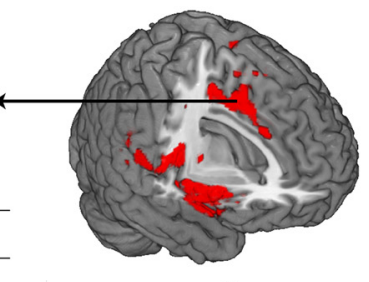

$x=3$

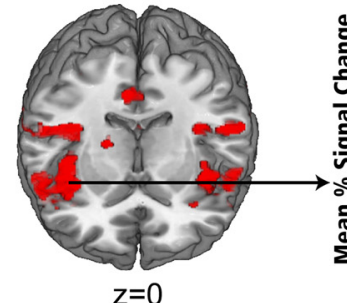

$\mathrm{z}=0$

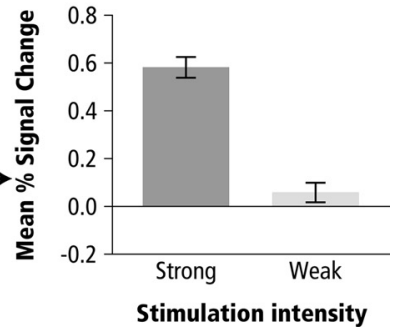

Figure 2. Evidence for efficacy of the threat-of-shock paradigm in inducing anticipatory anxiety. $\boldsymbol{a}, \mathrm{SCR}$ changes due to threat-of-shock manipulation. The plots show mean ( \pm SEM) SCRs during choices under threat of shock (left) and during the experience of the electrical shocks (right). Significantly increased SCRs were observed for choices during the anticipation of strong compared with weak stimulation, and following strong versus weak stimulation. This demonstrates the psychological and physiological efficacy of the threat-of-shock manipulation. $\boldsymbol{b}$, Influence of choice and threat-of-shock manipulation on reaction times. RTs were decreased under anticipatory anxiety and for choices of the lottery option. c, Neural correlates of strong versus weak electrical stimulation. Strong compared with weak stimulation intensity led to activation of the "pain matrix," including bilateral insula, anterior and middle cingulate cortices, right somatosensory cortex, and cerebellum $(p<0.05$, FEW corrected). Mean ( \pm SEM) $\beta$ estimates extracted from middle cingulate cortex $(x=14, y=-33, z=46$; left) and from right insula $(x=41, y=-1, z=-5)$ showed a signal increase during strong electrical stimulation and no signal increase during weak stimulation. These activation patterns due to strong versus weak electrical stimulation demonstrate the physiological effectiveness of the threat-of-shock manipulation. ${ }^{* *} p<0.01,{ }^{* * *} p<0.001$.

and loss amounts, as well as relevant two-way interaction terms. Importantly, RTs during first versus second presentations were not significantly different (order coefficient: $-14.438, T=$ $-0.13, p=0.895$ ) and were similarly affected by affective context (Affective Context $\times$ Order coefficient: 40.4184, $T=1.41, p=$ 0.159 ), possible gains (Gains $\times$ Order coefficient: $-1.809, T=$ $-0.70, p=0.481$ ), and possible losses (Losses $\times$ Order coefficient: $-0.148, T=-0.04, p=0.966)$. These results suggest that participants did not respond from memory for the second presentations of the lotteries but rather actively evaluated all lotteries. This conclusion is further backed up by our finding of robust value signals in the BOLD data (see below).

\section{Anticipatory anxiety shifts the focus of neural valuation from} positive ESV to negative ESV coding

Even though anticipatory anxiety did not change overt behavior, it may nevertheless have affected the way the brain valued the choice options during decision making. Initial analysis confirmed our expectation that, when pooling across threat and safe trials, ESV correlated positively with activity in the $\operatorname{VMPFC}(x=2, y=47, z=-8$, $T=3.34$ ) and the VS (subregion 1: $x_{1}=3, y_{1}=11, z_{1}=-8, T=$ 3.59; subregion 2: $\left.x_{2}=-5, y_{2}=12, z_{2}=-5, T=3.42\right)$. However, when directly comparing neural correlates of ESV between threat and safe trials, we found that anticipatory anxiety led to a significant disruption of ESV coding in both VMPFC $(x=-3, y=39, z=-5$, $T=3.59$; Fig. 4a,c) and VS $(x=6, y=6, z=-6$; $T=3.24$; Fig. 4a, $d)$. To characterize this interaction effect, we investigated parametric correlations between BOLD and ESV during threat and safe trials separately. Both the VMPFC and VS coded ESV during safe trials (VMPFC: $x=-3, y=40, z=-8, T=3.87$; VS: $x=6, y=6, z=-6$, $T=4.56$ ) but not during threat trials (no significant ESV-related activity was found in those regions). Moreover, a conjunction analysis of the ESV contrast images during threat and safe trials did not reveal any activity in these regions. 
A very different pattern of results was observed in right anterior insula, where ESV coding also differed between both affective contexts $(x=39, y=0, z=0 ; T=$ 3.25; Fig. $4 b, e)$. Separate analyses of neural signals during both contexts revealed that ESV was not significantly correlated with BOLD signals during safe trials (no voxel was found), but was instead negatively correlated with BOLD signals during threat trials (left insula cluster $1: x=-30$, $y=21, z=13, T=3.48$; left insula cluster 2: $x=-40, y=20, z=4, T=3.38$; right insula: $x=39, y=-12, z=-6, T=$ 3.44). Again, a conjunction analysis of the ESV contrast images during threat and safe trials did not reveal any activity in this area. Thus, during anticipatory anxiety, the insula increased its activity for smaller $U(x)$, and therefore for larger, potentially negative outcomes. Anticipatory anxiety therefore led to a qualitatively distinct style of neural value coding by disrupting positive value coding in the VMPFC and the VS while simultaneously enhancing negative value coding in the anterior insula.

\section{Anticipatory anxiety changes trial-by- trial relationship between neural signal in ROIs and economic choice}

The fMRI results described above identi-

fied regions in the VMPFC, VS, and insula where neural activity correlated with different aspects of subjective values during the two affective contexts (positive ESVs during safe trials and negative ESVs during threat trials). As a next step, we corroborated that the change in neural coding in these regions between both contexts is tightly linked to behavior. For this analysis, we extracted the neural activity for each trial from the ROIs in the VMPFC, VS, and insula, and regressed the choice outcomes for each trial on the activity in each region, the affective context, and the interaction of both variables (see Materials and Methods). Before this analysis, we ensured that the ROI data could replicate the results of the SPM analysis by performing a regression of neural activity in each region on subjective values, affective context, and their interaction. Importantly, the ROIs for both analyses were similarly defined using the well established leave-onesubject-out approach (Esterman et al., 2010), which avoids circularity and enabled us to perform this prediction analysis with independent data (see Materials and Methods).

The independent ROI analysis clearly confirmed the results of the SPM analysis. As illustrated in Figure 4, all regions showed a negative change in value coding from the safe to the threat context, as indicated by a significant interaction between subjective value and threat (VMPFC: interaction coefficient $=-0.0071$, $T=-2.70, p=0.0035$; VS: interaction coefficient $=-0.0046$, $T=-1.99, p=0.0231$; insula: interaction coefficient $=$ $-0.0077, T=-2.01, p=0.0221)$. Importantly, the pattern of this interaction was different for the insula compared with the VS and the VMPFC (Fig. 4). Whereas the signal in VMPFC and VS tracked ESVs during the safe condition and was suppressed under conditions of threat (VMPFC: $\mathrm{ESV}_{S}$ coefficient $=0.0057, T=$ 2.77, $p=0.0028 ; \mathrm{ESV}_{T}$ coefficient $=-0.0014, T=-0.77, p=$
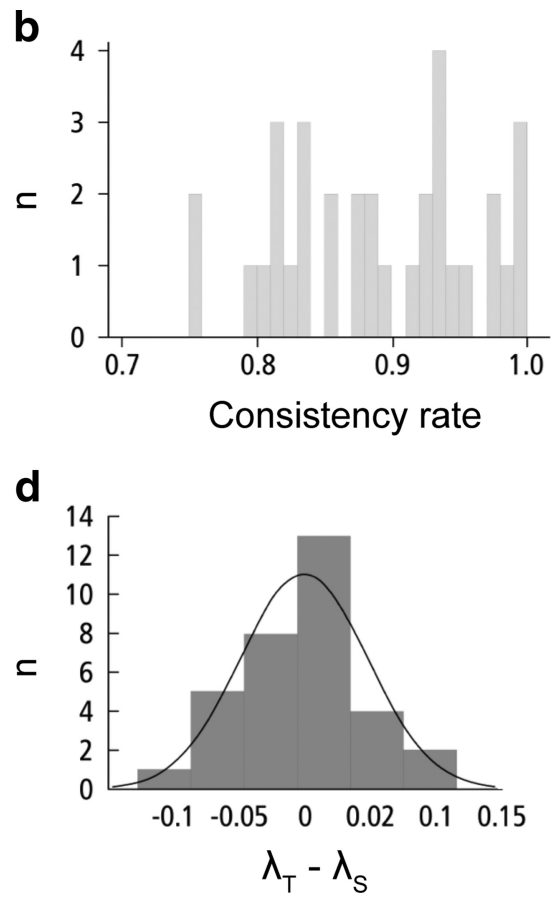

Safe

$$
\lambda_{\mathrm{T}}-\lambda_{\mathrm{S}}
$$

Figure 3. Effects of the threat-of-shock manipulation on choices. $\boldsymbol{a}$, Gambling rates (mean \pm SEM) did not differ for the two affective contexts. $\boldsymbol{b}$, Histogram of participants' consistency rates [match of responses (in percentages) for the identical choices across contexts. Average + SEM loss aversion parameter $\lambda$ across both contexts. Both threat and safe trials led to similar degrees ass aversion. $\boldsymbol{d}$, Histogram of the participants' changes in loss aversion due to the affective manipulation. The changes were not different from zero and normally distributed [mean $\lambda_{S}-\lambda_{T}=-0.0007$ (SEM $\left.=0.0085\right)$ ]. Thus, the analysis of different behavioral parameters revealed the stability of choice across affective contexts.

0.2201; VS: $\mathrm{ESV}_{S}$ coefficient $=0.0050, T=3.95, p<0.0001$; $\mathrm{ESV}_{T}$ coefficient $=0.0004, T=0.25, p=0.4028$ ), activity in the insula did not track value during safe trials but coded negative subjective value during the threat condition (insula: $\mathrm{ESV}_{S}$ coefficient $=0.0024, T=0.86, p=0.194 ; \mathrm{ESV}_{T}$ coefficient $=-0.0052$, $T=-1.98, p=0.0239$ ). These results from the independent ROIs thus fully confirm the relationship between subjective values and regional signals in VMPFC, VS, and insula.

Next, we tested whether trial-by-trial signal changes within our ROIs in the valuation network directly map onto actual economic decisions. We predicted that the trial-by-trial signal within these independent regions not only reflects subjective values, but can also directly predict observed choices. In line with all previous results, we expected that decision outcomes in the absence of threat should be predicted only by the VMPFC and VS signal, but in the presence of threat only by insula activity. In line with this prediction, we found significant interactions between neural signal and threat for VMPFC (interaction coefficient $=-0.246$, Wald $Z=-2.54, p=0.0056$ ) and insula (interaction coefficient $=-0.1162$, Wald $Z=-1.71, p=0.044)$. As illustrated in Figure $5 a$, VMPFC neural signals predicted choice only during safe trials ( safe coefficient $=0.1876$, Wald $Z=3.35, p=0.0004$ ) but not during threat trials (threat coefficient $=-0.0550$, Wald $Z=-0.79, p=0.2161$ ), whereas the opposite pattern was obtained in the insula ( safe coefficient $=0.0302$, Wald $Z=0.69, p=$ 0.24475 ; threat coefficient $=-0.089$, Wald $Z=-1.84 ; p=$ $0.033)$. The corresponding interaction in the ventral striatum was weaker and nonsignificant (interaction coefficient $=-0.125$, Wald $Z=-0.82, p=0.206$ ), perhaps due to greater noise in the signals extracted from this small region. Nevertheless, in analogy to the VMPFC and again, consistent with our hypothesis, neural 


\section{a}

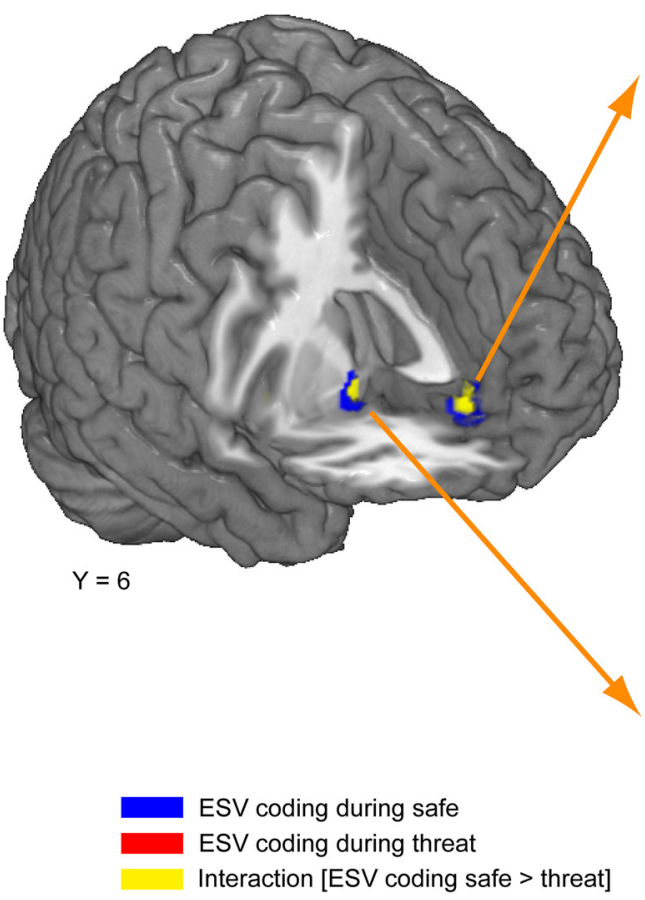

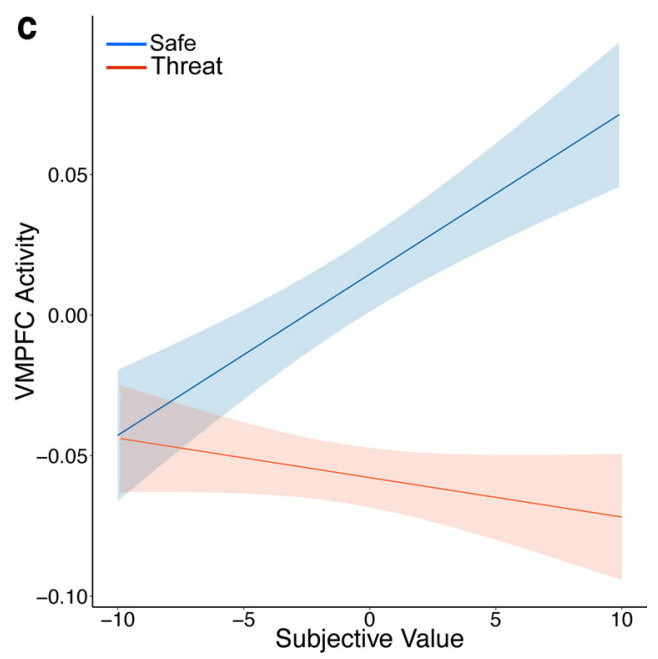

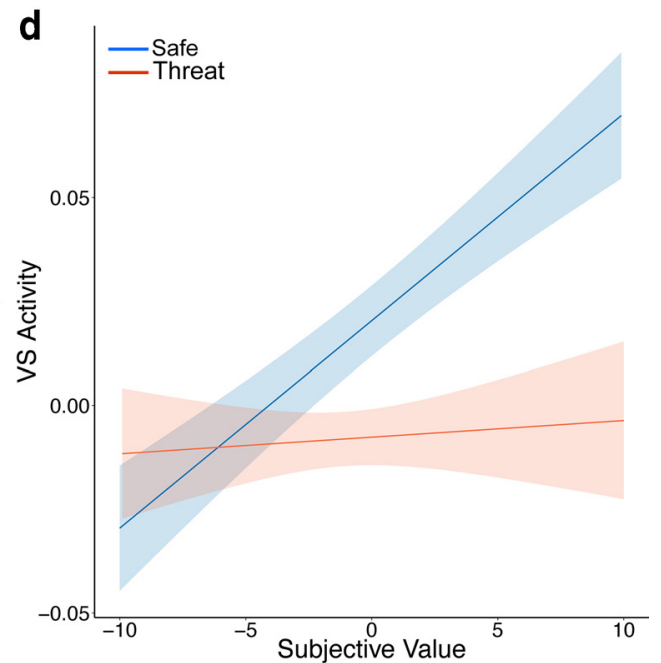

e

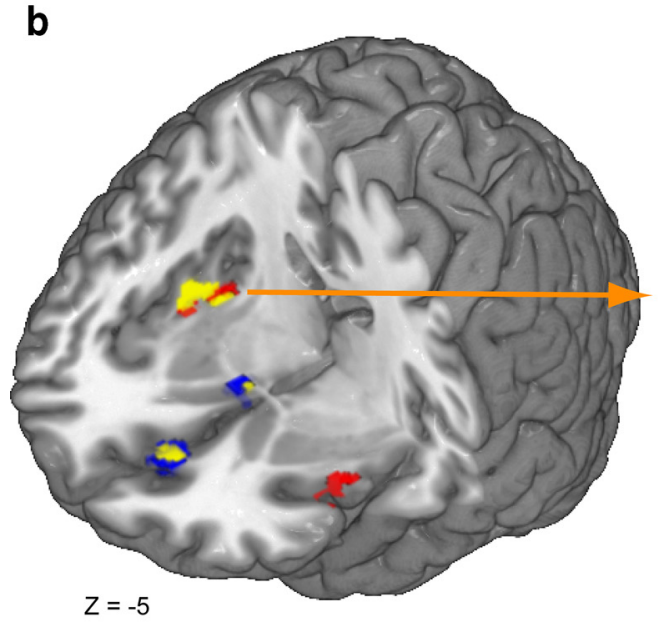

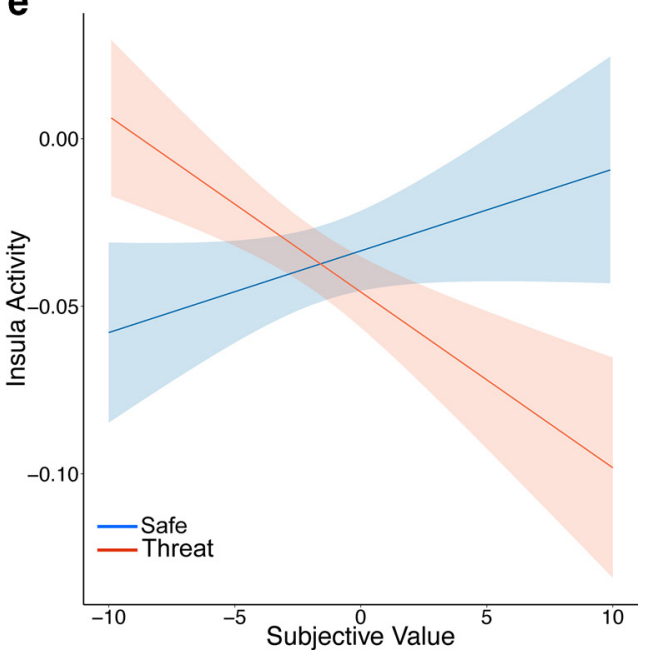

Figure 4. Changes in the correlation of regional BOLD signals with subjective values due to threat of shock (interaction contrast, $\left.\operatorname{ESV}_{S}>\operatorname{ESV}_{T}\right)$. Such changes were observed in $\boldsymbol{a}[\mathrm{VMPFC}(x=-3$, $y=39, z=-5)$, and VS $(x=6, y=6, z=-6)$ ] as well as $\boldsymbol{b}$ insula $(x=39, y=0, z=0)$. Voxels in blue show positive correlation with subjective value during safe trials, voxels in red show negative correlations with SV during threat trials, and voxels in yellow show a significant interaction. $\mathbf{c}-\boldsymbol{e}$, ROI analyses confirm the pattern of interactions found in the SPM analyses. To avoid circularity, a LOSO approach was used to extract $\beta$ weights from independent ROIs (see text for details). The plots show the average trial-by-trial relationship (lines \pm SEM as shaded area) between regional activity and subjective value, as estimated in regression analyses of these betas (see main text). For both VMPFC (c) and VS (d), positive correlations between subjective value and BOLD activity were present in safe trials, but were significantly weaker (and, in fact, absent) during threat trials. e, In contrast, the insula showed no correlation with subjective value coding during safe trials, but significantly stronger negative value coding (increasing activity for decreasing expected subjective value) during threat trials. These findings suggest that anticipatory anxiety caused a distinct style of neural value coding by disrupting positive value coding in the VMPFC and the VS, and simultaneously enhancing negative value coding in the anterior insula. All imaging results are displayed at $p<0.005$ for display purposes. The shaded error bars reflect robust and clustered SEM. 
a

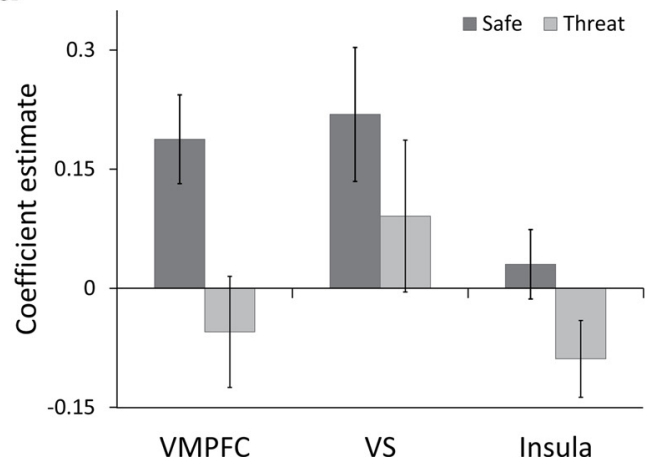

b
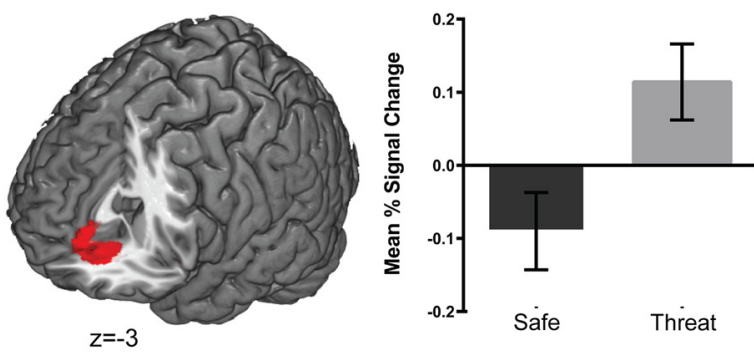

Figure 5. a, Results from logistic regressions predicting choice based on regional activity in VMPFC, VS, and insula. Both VMPFC and VS predict choice only during safe trials, but not during threat trials. In contrast, the insula shows the opposite pattern of predicting choice (negatively) only during threat trials, but not during safe trials. $\boldsymbol{b}$, Decreases in average VMPFC BOLD signals during choices due to threat of shock $\left(T_{S}>T_{T}\right)$. Anticipation of strong electrical stimulation led to general BOLD signal reduction in VMPFC $(x=-8, y=35, z=-2)$ pooled across all ESV levels. Anticipatory anxiety led to decreases in overall activity for valuation brain regions during choice, possibly due to the inherent negative value of the impending strong stimulation. The bar plot shows mean regression coefficients extracted from a $12 \mathrm{~mm}$ sphere around the VMPFC activation peak to illustrate the pattern of suppressed activity during choices in the threat versus safe context. The imaging results are displayed at $p<0.005$ for display purposes. Error bars reflect SEM.

signals in the VS predicted choices during safe trials (safe coefficient $=0.2189$, Wald $Z=2.60, p=0.0047$ ) but not during threat trials (threat coefficient $=0.0909$, Wald $Z=0.95, p=0.17095$; Fig. 5a). Together, these regression analyses therefore establish that the different patterns of neural ESV coding in the two affective contexts are both clearly linked to choice behavior. Moreover, all our results on neural valuation signals show that participants did compute subjective values for all choices, even though these computations were implemented in different cortical areas, depending on affective context. The presence of these context-dependent value computations makes it very unlikely that participants responded from memory on the $50 \%$ of trials where gambles were presented a second time.

\section{Negative baseline shifts in VMPFC during anticipatory anxiety}

What mechanism may underlie the breakdown of positive value coding under anticipatory anxiety? One possibility is that in the threat context, the processing of lottery values in the VS and VMPFC may interact with the negative emotional value associated with the anticipated uncomfortable stimulation (Talmi et al., 2009; Winecoff et al., 2013). Given the salience of anticipatory anxiety relative to lottery outcomes, the processing of the aversive emotional event can be expected to overshadow value coding with respect to probabilistic financial gains. If this were the case, then BOLD signals in the VS and VMPFC should be lower on average for threat compared with safe trials, pooled across all possible financial outcomes. We tested this conjecture by contrasting task-related activity in threat versus safe trials, independent of correlations with trial-wise ESV. Consistent with our conjecture, threat trials were associated with decreased taskrelated activations in VMPFC $(x=-8, y=35, z=-2 ; T=5.58$; Fig. $5 b)$, amygdala $(x=29, y=3, z=-29 ; T=4.56)$, and insula $(x=45, y=0, z=1 ; T=3.64, x=-45, y=-3, z=-2 ; T=$ 4.45). These observations confirm that anticipatory anxiety due to the impending strong stimulation can decrease the overall activation of valuation brain regions (Talmi et al., 2009). This may reduce the excitability of these brain regions for coding the positive values of probabilistic financial gains, as suggested by the observed breakdown of positive ESV coding in the threatening context.

\section{Anticipatory anxiety decreases functional connectivity in the valuation network}

If anticipatory anxiety disrupts the neural processing of possible financial outcomes during choice, then this may not only affect activity in single brain areas but also functional communication within the connected network of value-related brain areas. Thus, we hypothesized that the VMPFC may show reduced functional connectivity with other value-related brain regions during anticipatory anxiety. We formally tested this conjecture with PPI analyses of context-dependent changes in functional connectivity of the VMPFC (seeded at $x=-3, y=39, z=-5$, Fig. $6 a$ ) between threat and safe contexts. This revealed that threat contexts indeed lead to significantly decreased functional coupling of the VMPFC with the following two other key value-related brain areas: the VS $(x=-6, y=14, z=-11, T=3.64$; Fig. $6 b, c)$; and the insula $(x=-38, y=17, z=-8, T=4.9$; Fig. $6 b, d)$. This confirms that anticipatory anxiety disrupted positive ESV coding both at the level of local activity within areas of the value network, but also at the level of functional integration between these brain regions.

We also tested the hypothesis that anticipatory anxiety may change functional communication between valuation areas and regions outside the classic valuation system, which may possibly be involved in action selection regardless of affective context. For this purpose, we conducted PPI analyses based on seed regions in the VS (at $x=6, y=6, z=-6$ ), the insula (at $x=39, y=0, z=$ 0 ), and the dorsolateral prefrontal cortex (DLPFC; seeded at the DLPFC peak voxel in the neurosynth automated meta-analysis for the term cognitive control: $x=50, y=36, z=24)$. However, we did not find any reduction in functional connectivity between our areas of interest and other regions outside the classic valuation system. The unchanged functional involvement of cognitive control areas such as the DLPFC may perhaps reflect that neurons in the VMPFC and insula not only compute values, but also encode signals used for flexible choice and action selection (Paulus et al., 2005; Hunt et al., 2014; Strait et al., 2014). In any case, our results confirm that anticipatory anxiety during the threatening context disrupted positive ESV coding both at the level of local activity within areas of the value network, but also at the level of functional integration between these brain regions. 


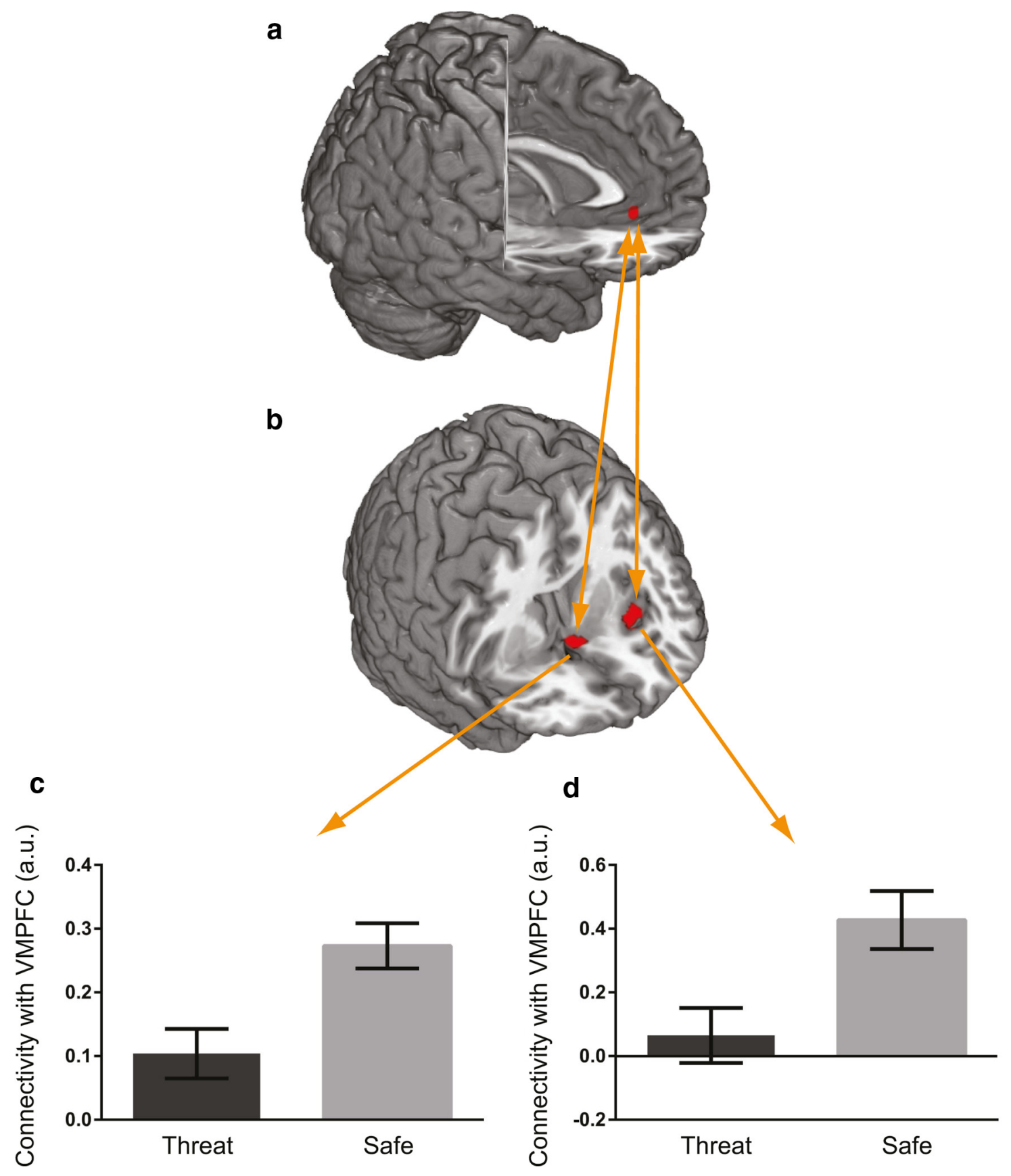

Figure 6. Changes in functional connectivity within the valuation network during anticipatory anxiety. $\boldsymbol{a}-\boldsymbol{c}$, Threat of shock led to decreased connectivity between the seed region in VMPFC $(x=$ $-3, y=39, y=-5 ; \boldsymbol{a})$ and both VS $(x=-6, y=14, z=-11, T=3.64 ; \boldsymbol{b}, \boldsymbol{c})$ and insula $(x=-38, y=17, z=-8, T=4.9 ; \boldsymbol{b}, \boldsymbol{d})$. Thus, anticipatory anxiety disrupted the functional integration of the valuation network of the brain. Error bars reflect SEM. All results are displayed at $p<0.005$ for display purposes. Error bars reflect the SEM.

\section{Discussion}

This study investigated how incidental anxiety can affect value-based decisions under risk. Purely behavioral effects of background emotions on choice are well documented in the clinical and psychology literature (Maner et al., 2007; Clark et al., 2012; Giorgetta et al., 2012; Grecucci et al., 2013) but have been less prominently investigated from the perspective of underlying neural activity (Pessoa and Pereira, 2013). Here we investigated this issue with an experimental threat-of-shock paradigm that allowed us to induce anticipatory anxiety in healthy participants while they took risky choices during fMRI. We find that this affective manipulation did not change overt choices, but fundamentally altered value coding in the brain. In the safe context, the expected subjective values of the gambles were coded positively in the VMPFC and VS. During the threat context, these processes collapsed and were replaced by negative value coding in the anterior insula (i.e., increased activity for increasingly worse outcomes). In general, our results are congruent with previous findings (Kim et al., 2011) that the VS and VMPFC can code subjective value in a positive manner, whereas the insula can show negative correlations with subjective values. However, our data show that these two types of value representations can be dissociated and may depend flexibly on the affective state, with a dominance of pos- 
itive value coding in the VMPFC and VS during neutral states, and a prevalence of negative value coding in the insula during negative affective states. This dependence of value coding on affective context may not have been evident in previous neuroimaging studies that measured value-related brain activity in just one affective context (usually neutral; for review, see Levy and Glimcher, 2011, 2012; Bartra et al., 2013). However, please note that both the diminished value sensitivity in VMPFC and its decreased communication with the striatum under anticipatory anxiety are clearly consistent with rodent studies that have demonstrated impaired value coding and reward learning under stress (Dias-Ferreira et al., 2009).

Strikingly, the shift in value coding between affective contexts was not accompanied by changes in revealed economic preferences, as measured by overt choice (only reaction times were affected). Nevertheless, our analyses revealed a tight link between neural value signals and behavior in both affective contexts, with neural activity in VMPFC and VS predicting choices only for safe trials, and neural activity in the insula predicting choices only for threat trials. Our results thus demonstrate that the same behavioral outcome can be realized through different neural valuecoding mechanisms. This finding is generally congruent with multiple-systems theories of decision making stating that different valuation systems can guide choice, depending on the properties of the decision-making situation (Rangel et al., 2008). That neural valuation processes can change during negative affective states is corroborated by findings (Schwabe et al., 2012) that hormonally induced stress can lead to a change from goal-directed to habitual decision control and reduced value sensitivity in medial prefrontal cortex. Our findings therefore suggest that during anxiety the same behavioral choices may have been brought about by goal-directed negative value computations in the insula (rather than positive value computations in the VMPC and VS), possibly in conjunction with compensatory mechanisms such as heuristics and increased habitual responding. In either case, we speculate that the reduction of value coding in the VMPFC and VS during anxiety may indicate a decrease in the positive value of the available choice options, even though such speculations need to be taken with caution given the problem of reverse inference in neuroimaging studies (Poldrack, 2011).

The conjecture that anticipatory anxiety may have decreased neural sensitivity for the subjective value of the choice-relevant stimuli is congruent with our findings of (1) a general negative baseline shift in VMPFC during threat and (2) reduced functional connectivity of this area with the insula and the VS. This assumption dovetails with the results of previous neuroimaging studies on the integration of emotional and economic value (Talmi et al., 2009; Park et al., 2011; Winecoff et al., 2013). Specifically, recent findings suggest that VMPFC signals track the emotional value of stimuli on the one hand (Winecoff et al., 2013) and economic value on the other (Levy and Glimcher, 2012). Moreover, Talmi et al. (2009) found decreased value signals in VMPFC for choices comprising a task-contingent painful stimulus. Here we show that even a fully incidental but highly salient and emotionally aversive event-the anticipation of painful electrical stimulation - can overshadow neural signals related to economic value computations. This supports the notion that emotional and economic value may be processed by the same VMPFC region, extending the hypothesis that the VMPFC encodes a standardized economic value signal to the domain of emotional value (Montague and Berns, 2002; Rangel and Hare,
2010). Moreover, our findings are consistent with suggestions that the VMPFC may compute subjective values even for certain task-irrelevant stimuli (Lebreton et al., 2009; Levy et al., 2011; Kühn and Gallinat, 2012) and that negative affective states (i.e., anxiety or stress) can lead to structural and functional changes in the VMPFC (Liston et al., 2006; McEwen, 2007).

However, it could be argued that the diminished VMPFC activity under anticipatory anxiety may not reflect changes in neural value processing but rather reduced default mode network (DMN) activity, as DMN activity is commonly observed in the VMPFC. However, this alternative explanation appears very unlikely. Inhibitions of DMN activity would be expressed in a whole network of regions comprising the VMPFC, posterior cingulate cortex (PCC), and temporoparietal junction (TPJ; Buckner et al., 2008; Andrews-Hanna et al., 2010; Li et al., 2014), would be accompanied by a concomitant increase in frontoparietal activity (Fox et al., 2005; Sridharan et al., 2008; Chen et al., 2013), and would be more marked in conditions with higher cognitive demand and thus longer reaction times (McKiernan et al., 2003). In our task, a negative baseline shift was found only in the VMPFC (but not in the PCC and TPJ) in the threat context that actually led to faster RTs (rather than increased demand indicated by slowed responses). The reductions in VMPFC signals found here are therefore more likely to indicate reduced positive value coding due to the high negative value of the impending painful stimulation.

Our results show that the functional changes due to the threat of shock not only affected the VMPFC in isolation but also its functional connectivity with other areas. This suggests weakened function of an entire valuation network (rather than single regions) under anticipatory anxiety. Viewed from this network perspective, the reduction in connectivity between VMPFC and insula may indicate a release from inhibition in the insula that may have resulted in stronger negative value coding during threat trials. Importantly, the insula showed two distinct types of signals in our study. One of these signals appeared related to valuation during threat trials, and consisted of a negative baseline shift and enhanced negative value coding (Sescousse et al., 2013; Tanaka et al., 2014). The other signal was elicited by the painful shocks when these were actually administered, reminiscent of the well reported activity in the so-called pain matrix (Tracey and Mantyh, 2007; Leknes and Tracey, 2008). We speculate that these two effects may reflect the involvement of separate neural populations, for two reasons. First, it is well established that the insula contains functionally diverse types of neurons (Chang et al., 2013; Uddin et al., 2014) that are nevertheless spatially intermingled. This may explain why in our data, the activation peaks for both types of signals were spatially separated ( $5 \mathrm{~mm}$ apart). Second, pain-processing neurons in the insula usually show positive baseline shifts during the anticipation and actual delivery of (predictable) painful shocks (Jones et al., 1992; Apkarian et al., 2005; Dalton et al., 2005; Carlsson et al., 2006; Choi et al., 2012). The negative baseline shifts found here during the threat blocks (with unpredictable stimulation) are thus more likely to reflect valuation processes, which is in line with findings that insula activity reflects value computations in other contexts (Sescousse et al., 2013; Tanaka et al., 2014) and is susceptible to stress during decision making (Lighthall et al., 2009, 2012).

Our study may have important implications for neurobiological perspectives on maladaptive anxiety and related psychopathology. Transient anxiety states normally carry adaptive value since they may increase vigilance and attention to possible negative outcomes that should be avoided. This functional anxiety, however, may turn into a maladaptive state if anxious behavior is 
permanently adopted and becomes detached from the environment (Grupe and Nitschke, 2013). We find that transient anxiety leads to a change in neural value coding in the absence of changes in overt behavior. This situation may resemble prodromal stages of anxiety disorders where no pathological decision making is evident, as the anxious persons might use compensatory strategies (e.g., increased focus on task or calculation) to overcome the pathological risk aversion typical for anxiety disorders (Maner et al., 2007; Giorgetta et al., 2012). Our findings suggest that during such early stages, a neural focus on negative value might not be accompanied by striking behavioral changes. However, the permanent adoption of these strategies might lead to gradual deterioration of the neural valuation system and/or compensatory strategies until behavioral deviations emerge. Similar mechanisms may be at play in depression, where early stages of the illness are associated with decreased hedonic capacity (indicated by changes in neural value processing) without observable aberrant decision making, whereas later stages are also often associated with altered value-based decision making (Treadway and Zald, 2011; Der-Avakian and Markou, 2012). This may be consistent with the assumption that a persistent focus on negative value coding due to the ongoing incidental negative affect may ultimately lead to a functional deterioration of the valuation system of the brain and therefore to changes of overt behavior. Thus, our findings suggest a pathway for the transition from adaptive to maladaptive emotional responses, as is commonly observed in anxiety and affective disorders (Paulus and Yu, 2012).

\section{References}

Andersson JL, Hutton C, Ashburner J, Turner R, Friston K (2001) Modeling geometric deformations in EPI time series. Neuroimage 13:903-919. CrossRef Medline

Andrews-Hanna JR, Reidler JS, Sepulcre J, Poulin R, Buckner RL (2010) Functional-anatomic fractionation of the brain's default network. Neuron 65:550-562. CrossRef Medline

Apkarian AV, Bushnell MC, Treede R-D, Zubieta J-K (2005) Human brain mechanisms of pain perception and regulation in health and disease. Eur J Pain 9:463-484. CrossRef Medline

Bach DR, Flandin G, Friston KJ, Dolan RJ (2009) Time-series analysis for rapid event-related skin conductance responses. J Neurosci Methods 184: 224-234. CrossRef Medline

Bartra O, McGuire JT, Kable JW (2013) The valuation system: a coordinatebased meta-analysis of BOLD fMRI experiments examining neural correlates of subjective value. Neuroimage 76:412-427. CrossRef Medline

Berns GS, Capra CM, Chappelow J, Moore S, Noussair C (2008) Nonlinear neurobiological probability weighting functions for aversive outcomes. Neuroimage 39:2047-2057. CrossRef Medline

Borkenau P, Ostendorf F (1993) NEO-Fünf-Faktoren-Inventar (NEO-FFI) nach Costa und McCrae. Göttingen, Germany: Hogrefe.

Bruhin A, Fehr-Duda H, Epper T (2010) Risk and rationality: uncovering heterogeneity in probability distortion. Econometrica 78:1375-1412. CrossRef

Buckner RL, Andrews-Hanna JR, Schacter DL (2008) The brain's default network: anatomy, function, and relevance to disease. Ann N Y Acad Sci 1124:1-38. CrossRef Medline

Capra CM, Jiang B, Engelmann JB, Berns GS (2013) Can personality type explain heterogeneity in probability distortions? J Neurosci Psychol Econ 6:151-166. CrossRef Medline

Carlsson K, Andersson J, Petrovic P, Petersson KM, Ohman A, Ingvar M (2006) Predictability modulates the affective and sensory-discriminative neural processing of pain. Neuroimage 32:1804-1814. CrossRef Medline

Chang LJ, Yarkoni T, Khaw MW, Sanfey AG (2013) Decoding the role of the insula in human cognition: functional parcellation and large-scale reverse inference. Cereb Cortex 23:739-749. CrossRef Medline

Chen AC, Oathes DJ, Chang C, Bradley T, Zhou ZW, Williams LM, Glover GH, Deisseroth K, Etkin A (2013) Causal interactions between frontoparietal central executive and default-mode networks in humans. Proc Natl Acad Sci U S A 110:19944-19949. CrossRef Medline
Choi JM, Padmala S, Pessoa L (2012) Impact of state anxiety on the interaction between threat monitoring and cognition. Neuroimage 59:19121923. CrossRef Medline

Clark L, Li R, Wright CM, Rome F, Fairchild G, Dunn BD, Aitken MR (2012) Risk-avoidant decision making increased by threat of electric shock. Psychophysiology 49:1436-1443. CrossRef Medline

Cox RW (1996) AFNI: software for analysis and visualization of functional magnetic resonance neuroimages. Comput Biomed Res 29:162-173. CrossRef Medline

Dalton KM, Kalin NH, Grist TM, Davidson RJ (2005) Neural-cardiac coupling in threat-evoked anxiety. J Cogn Neurosci 17:969-980. CrossRef Medline

Deichmann R, Gottfried JA, Hutton C, Turner R (2003) Optimized EPI for fMRI studies of the orbitofrontal cortex. Neuroimage 19:430-441. CrossRef Medline

De Martino B, Kumaran D, Seymour B, Dolan RJ (2006) Frames, biases, and rational decision-making in the human brain. Science 313:684-687. CrossRef Medline

Der-Avakian A, Markou A (2012) The neurobiology of anhedonia and other reward-related deficits. Trends Neurosci 35:68-77. CrossRef Medline

Dias-Ferreira E, Sousa JC, Melo I, Morgado P, Mesquita AR, Cerqueira JJ, Costa RM, Sousa N (2009) Chronic stress causes frontostriatal reorganization and affects decision-making. Science 325:621-625. CrossRef Medline

Di Martino A, Scheres A, Margulies DS, Kelly AM, Uddin LQ, Shehzad Z, Biswal B, Walters JR, Castellanos FX, Milham MP (2008) Functional connectivity of human striatum: a resting state FMRI study. Cereb Cortex 18:2735-2747. CrossRef Medline

Dreher JC, Kohn P, Kolachana B, Weinberger DR, Berman KF (2009) Variation in dopamine genes influences responsivity of the human reward system. Proc Natl Acad Sci U S A 106:617-622. CrossRef Medline

Engelmann JB, Maciuba B, Vaughan C, Paulus MP, Dunlop BW (2013) Posttraumatic stress disorder increases sensitivity to long term losses among patients with major depressive disorder. PLoS One 8:e78292. CrossRef Medline

Esterman M, Tamber-Rosenau BJ, Chiu YC, Yantis S (2010) Avoiding nonindependence in fMRI data analysis: leave one subject out. Neuroimage 50:572-576. CrossRef Medline

Fossati P (2012) Neural correlates of emotion processing: from emotional to social brain. Eur Neuropsychopharmacol 22 [Suppl 3]:S487-S491. CrossRef Medline

Fox MD, Snyder AZ, Vincent JL, Corbetta M, Van Essen DC, Raichle ME (2005) The human brain is intrinsically organized into dynamic, anticorrelated functional networks. Proc Natl Acad Sci U S A 102:9673-9678. CrossRef Medline

Friston KJ, Holmes AP, Worsley KJ, Poline J-P, Frith CD, Frackowiak RSJ (1994) Statistical parametric maps in functional imaging: a general linear approach. Hum Brain Mapp 2:189-210. CrossRef

Giorgetta C, Grecucci A, Zuanon S, Perini L, Balestrieri M, Bonini N, Sanfey AG, Brambilla P (2012) Reduced risk-taking behavior as a trait feature of anxiety. Emotion 12:1373-1383. CrossRef Medline

Gitelman DR, Penny WD, Ashburner J, Friston KJ (2003) Modeling regional and psychophysiologic interactions in fMRI: the importance of hemodynamic deconvolution. Neuroimage 19:200-207. CrossRef Medline

Grecucci A, Giorgetta C, Brambilla P, Zuanon S, Perini L, Balestrieri M, Bonini N, Sanfey AG (2013) Anxious ultimatums: how anxiety disorders affect socioeconomic behaviour. Cogn Emot 27:230-244. CrossRef Medline

Grupe DW, Nitschke JB (2013) Uncertainty and anticipation in anxiety: an integrated neurobiological and psychological perspective. Nat Rev Neurosci 14:488-501. CrossRef Medline

Harlé KM, Allen JJB, Sanfey AG (2010) The impact of depression on social economic decision-making. J Abnorm Psychol 119:440-446. CrossRef Medline

Harlé KM, Chang LJ, van 't Wout M, Sanfey AG (2012) The neural mechanisms of affect infusion in social economic decision-making: a mediating role of the anterior insula. Neuroimage 61:32-40. CrossRef Medline

Hartley CA, Phelps EA (2012) Anxiety and decision-making. Biol Psychiatry 72:113-118. CrossRef Medline

Hautzinger M, Bailer M, Worall H, Keller F (1995) Beck-DepressionsInventar (BDI). Testhandbuch, Ed 2. Bern, Switzerland: Hans Huber. 
Henson RN, Price CJ, Rugg MD, Turner R, Friston KJ (2002) Detecting latency differences in event-related BOLD responses: application to words versus nonwords and initial versus repeated face presentations. Neuroimage 15:83-97. CrossRef Medline

Hsu M, Bhatt M, Adolphs R, Tranel D, Camerer CF (2005) Neural systems responding to degrees of uncertainty in human decision-making. Science 310:1680-1683. CrossRef Medline

Hunt LT, Dolan RJ, Behrens TE (2014) Hierarchical competitions subserving multi-attribute choice. Nat Neurosci 17:1613-1622. CrossRef Medline

Huys QJ, Pizzagalli DA, Bogdan R, Dayan P (2013) Mapping anhedonia onto reinforcement learning: a behavioural meta-analysis. Biol Mood Anxiety Disord 3:12. CrossRef Medline

Jenison RL, Rangel A, Oya H, Kawasaki H, Howard MA (2011) Value encoding in single neurons in the human amygdala during decision making. J Neurosci 31:331-338. CrossRef Medline

Jones AK, Friston K, Frackowiak RS (1992) Localization of responses to pain in human cerebral cortex. Science 255:215-216. CrossRef Medline

Kahneman D, Tversky A (1979) Prospect theory: an analysis of decision under risk. Econometrica 47:263. CrossRef

Kang MJ, Rangel A, Camus M, Camerer CF (2011) Hypothetical and real choice differentially activate common valuation areas. J Neurosci 31:461468. CrossRef Medline

Kelly C, de Zubicaray G, Di Martino A, Copland DA, Reiss PT, Klein DF, Castellanos FX, Milham MP, McMahon K (2009) L-DOPA modulates functional connectivity in striatal cognitive and motor networks: a double-blind placebo-controlled study. J Neurosci 29:7364-7378. CrossRef Medline

Kim H, Shimojo S, O'Doherty JP (2011) Overlapping responses for the expectation of juice and money rewards in human ventromedial prefrontal cortex. Cereb Cortex 21:769-776. CrossRef Medline

Knutson B, Wimmer GE, Kuhnen CM, Winkielman P (2008) Nucleus accumbens activation mediates the influence of reward cues on financial risk taking. Neuroreport 19:509-513. CrossRef Medline

Kriegeskorte N, Simmons WK, Bellgowan PS, Baker CI (2009) Circular analysis in systems neuroscience: the dangers of double dipping. Nat Neurosci 12:535-540. CrossRef Medline

Kühn S, Gallinat J (2012) The neural correlates of subjective pleasantness. Neuroimage 61:289-294. CrossRef Medline

Kuhnen CM, Knutson B (2005) The neural basis of financial risk taking. Neuron 47:763-770. CrossRef Medline

Lebreton M, Jorge S, Michel V, Thirion B, Pessiglione M (2009) An automatic valuation system in the human brain: evidence from functional neuroimaging. Neuron 64:431-439. CrossRef Medline

Lee D, Seo H, Jung MW (2012) Neural basis of reinforcement learning and decision making. Annu Rev Neurosci 35:287-308. CrossRef Medline

Leknes S, Tracey I (2008) A common neurobiology for pain and pleasure. Nat Rev Neurosci 9:314-320. CrossRef Medline

Levallois C, Clithero JA, Wouters P, Smidts A, Huettel SA (2012) Translating upwards: linking the neural and social sciences via neuroeconomics. Nat Rev Neurosci 13:789-797. CrossRef Medline

Levy DJ, Glimcher PW (2011) Comparing apples and oranges: using reward-specific and reward-general subjective value representation in the brain. J Neurosci 31:14693-14707. CrossRef Medline

Levy DJ, Glimcher PW (2012) The root of all value: a neural common currency for choice. Curr Opin Neurobiol 22:1027-1038. CrossRef Medline

Levy I, Snell J, Nelson AJ, Rustichini A, Glimcher PW (2010) Neural representation of subjective value under risk and ambiguity. J Neurophysiol 103:1036-1047. CrossRef Medline

Levy I, Lazzaro SC, Rutledge RB, Glimcher PW (2011) Choice from nonchoice: predicting consumer preferences from blood oxygenation leveldependent signals obtained during passive viewing. J Neurosci 31:118-125. CrossRef Medline

Li W, Mai X, Liu C (2014) The default mode network and social understanding of others: what do brain connectivity studies tell us. Front Hum Neurosci 8:74. CrossRef Medline

Lighthall NR, Mather M, Gorlick MA (2009) Acute stress increases sex differences in risk seeking in the balloon analogue risk task. PLoS One 4:e6002. CrossRef Medline

Lighthall NR, Sakaki M, Vasunilashorn S, Nga L, Somayajula S, Chen EY, Samii N, Mather M (2012) Gender differences in reward-related deci- sion processing under stress. Soc Cogn Affect Neurosci 7:476-484. CrossRef Medline

Lilliefors HW (1967) On the Kolmogorov-Smirnov test for normality with mean and variance unknown. J Am Stat Assoc 62:399. CrossRef

Lin A, Adolphs R, Rangel A (2012) Social and monetary reward learning engage overlapping neural substrates. Soc Cogn Affect Neurosci 7:274281. CrossRef Medline

Liston C, Miller MM, Goldwater DS, Radley JJ, Rocher AB, Hof PR, Morrison $\mathrm{JH}, \mathrm{McEwen}$ BS (2006) Stress-induced alterations in prefrontal cortical dendritic morphology predict selective impairments in perceptual attentional set-shifting. J Neurosci 26:7870-7874. CrossRef Medline

Litt A, Plassmann H, Shiv B, Rangel A (2011) Dissociating valuation and saliency signals during decision-making. Cereb Cortex 21:95-102. CrossRef Medline

Maner JK, Richey JA, Cromer K, Mallott M, Lejuez CW, Joiner TE, Schmidt NB (2007) Dispositional anxiety and risk-avoidant decision-making. Pers Individ Dif 42:665-675. CrossRef

McEwen BS (2007) Physiology and neurobiology of stress and adaptation: central role of the brain. Physiol Rev 87:873-904. CrossRef Medline

McKiernan KA, Kaufman JN, Kucera-Thompson J, Binder JR (2003) A parametric manipulation of factors affecting task-induced deactivation in functional neuroimaging. J Cogn Neurosci 15:394-408. CrossRef Medline

McLaren DG, Ries ML, Xu G, Johnson SC (2012) A generalized form of context-dependent psychophysiological interactions (gPPI): a comparison to standard approaches. Neuroimage 61:1277-1286. CrossRef Medline

Minassian A, Paulus MP, Perry W (2004) Increased sensitivity to error during decision-making in bipolar disorder patients with acute mania. J Affect Disord 82:203-208. CrossRef Medline

Minati L, Grisoli M, Franceschetti S, Epifani F, Granvillano A, Medford N, Harrison NA, Piacentini S, Critchley HD (2012a) Neural signatures of economic parameters during decision-making: a functional MRI (FMRI), electroencephalography (EEG) and autonomic monitoring study. Brain Topogr 25:73-96. CrossRef Medline

Minati L, Grisoli M, Seth AK, Critchley HD (2012b) Decision-making under risk: a graph-based network analysis using functional MRI. Neuroimage 60:2191-2205. CrossRef Medline

Montague PR, Berns GS (2002) Neural economics and the biological substrates of valuation. Neuron 36:265-284. CrossRef Medline

Park SQ, Kahnt T, Rieskamp J, Heekeren HR (2011) Neurobiology of value integration: when value impacts valuation. J Neurosci 31:9307-9314. CrossRef Medline

Patton JH, Stanford MS, Barratt ES (1995) Factor structure of the Barratt impulsiveness scale. J Clin Psychol 51:768-774. CrossRef Medline

Paulus MP, Yu AJ (2012) Emotion and decision-making: affect-driven belief systems in anxiety and depression. Trends Cogn Sci 16:476-483. CrossRef Medline

Paulus MP, Feinstein JS, Leland D, Simmons AN (2005) Superior temporal gyrus and insula provide response and outcome-dependent information during assessment and action selection in a decision-making situation. Neuroimage 25:607-615. CrossRef Medline

Pessoa L, Pereira M (2013) Cognition-emotion interactions: a review of the functional magnetic resonance imaging literature. In: Handbook of cognition and emotion (Robinson MD, Watkins ER, Harmon-Jones E, eds), pp 55-68. New York: Guilford.

Plassmann H, O'Doherty JP, Rangel A (2010) Appetitive and aversive goal values are encoded in the medial orbitofrontal cortex at the time of decision making. J Neurosci 30:10799-10808. CrossRef Medline

Poldrack RA (2011) Inferring mental states from neuroimaging data: from reverse inference to large-scale decoding. Neuron 72:692-697. CrossRef Medline

Preuschoff K, Quartz SR, Bossaerts P (2008) Human insula activation reflects risk prediction errors as well as risk. J Neurosci 28:2745-2752. CrossRef Medline

Pruessmann KP, Weiger M, Scheidegger MB, Boesiger P (1999) SENSE: sensitivity encoding for fast MRI. Magn Reson Med 42:952-962. CrossRef Medline

Rangel A, Hare T (2010) Neural computations associated with goal-directed choice. Curr Opin Neurobiol 20:262-270. CrossRef Medline

Rangel A, Camerer C, Montague PR (2008) A framework for studying the neurobiology of value-based decision making. Nat Rev Neurosci 9:545556. CrossRef Medline 
Rick S, Loewenstein GF (2008) The role of emotion in economic behavior. In: Handbook of emotions, Ed 3. New York: Guilford.

Robinson OJ, Letkiewicz AM, Overstreet C, Ernst M, Grillon C (2011) The effect of induced anxiety on cognition: threat of shock enhances aversive processing in healthy individuals. Cogn Affect Behav Neurosci 11:217227. CrossRef Medline

Robinson OJ, Overstreet C, Charney DR, Vytal K, Grillon C (2013a) Stress increases aversive prediction error signal in the ventral striatum. Proc Natl Acad Sci U S A 110:4129-4133. CrossRef Medline

Robinson OJ, Vytal K, Cornwell BR, Grillon C (2013b) The impact of anxiety upon cognition: perspectives from human threat of shock studies. Front Hum Neurosci 7:203. CrossRef Medline

Rushworth MF, Kolling N, Sallet J, Mars RB (2012) Valuation and decisionmaking in frontal cortex: one or many serial or parallel systems? Curr Opin Neurobiol 22:946-955. CrossRef Medline

Schmitz A, Grillon C (2012) Assessing fear and anxiety in humans using the threat of predictable and unpredictable aversive events (the NPU-threat test). Nat Protoc 7:527-532. CrossRef Medline

Schwabe L, Tegenthoff M, Höffken O, Wolf OT (2012) Simultaneous glucocorticoid and noradrenergic activity disrupts the neural basis of goaldirected action in the human brain. J Neurosci 32:10146-10155. CrossRef Medline

Sescousse G, Caldú X, Segura B, Dreher JC (2013) Processing of primary and secondary rewards: a quantitative meta-analysis and review of human functional neuroimaging studies. Neurosci Biobehav Rev 37:681-696. CrossRef Medline

Sharp C, Monterosso J, Montague PR (2012) Neuroeconomics: a bridge for translational research. Biol Psychiatry 72:87-92. CrossRef Medline

Singer T, Seymour B, O’Doherty J, Kaube H, Dolan RJ, Frith CD (2004) Empathy for pain involves the affective but not sensory components of pain. Science 303:1157-1162. CrossRef Medline

Sokol-Hessner P, Hsu M, Curley NG, Delgado MR, Camerer CF, Phelps EA (2009) Thinking like a trader selectively reduces individuals' loss aversion. Proc Natl Acad Sci U S A 106:5035-5040. CrossRef Medline

Sokol-Hessner P, Hutcherson C, Hare T, Rangel A (2012) Decision value computation in DLPFC and VMPFC adjusts to the available decision time. Eur J Neurosci 35:1065-1074. CrossRef Medline

Sokol-Hessner P, Camerer CF, Phelps EA (2013) Emotion regulation re- duces loss aversion and decreases amygdala responses to losses. Soc Cogn Affect Neurosci 8:341-350. CrossRef Medline

Spielberger CD, Gorsuch RL, Lushene R, Vagg PR, Jacobs GA (1983) Manual for the state-trait anxiety inventory. Palo Alto, CA: Consulting Psychologists.

Sridharan D, Levitin DJ, Menon V (2008) A critical role for the right frontoinsular cortex in switching between central-executive and default-mode networks. Proc Natl Acad Sci U S A 105:12569-12574. CrossRef Medline

Strait CE, Blanchard TC, Hayden BY (2014) Reward value comparison via mutual inhibition in ventromedial prefrontal cortex. Neuron 82:13571366. CrossRef Medline

Talmi D, Dayan P, Kiebel SJ, Frith CD, Dolan RJ (2009) How humans integrate the prospects of pain and reward during choice. J Neurosci 29: 14617-14626. CrossRef Medline

Tanaka SC, Yamada K, Yoneda H, Ohtake F (2014) Neural mechanisms of gain-loss asymmetry in temporal discounting. J Neurosci 34:5595-5602. CrossRef Medline

Thaler RH, Johnson EJ (1990) Gambling with the house money and trying to break even: the effects of prior outcomes on risky choice. Manag Sci 36:643-660. CrossRef

Tom SM, Fox CR, Trepel C, Poldrack RA (2007) The neural basis of loss aversion in decision-making under risk. Science 315:515-518. CrossRef Medline

Tracey I, Mantyh PW (2007) The cerebral signature for pain perception and its modulation. Neuron 55:377-391. CrossRef Medline

Treadway MT, Zald DH (2011) Reconsidering anhedonia in depression: lessons from translational neuroscience. Neurosci Biobehav Rev 35:537555. CrossRef Medline

Uddin LQ, Kinnison J, Pessoa L, Anderson ML (2014) Beyond the tripartite cognition-emotion-interoception model of the human insular cortex. J Cogn Neurosci 26:16-27. CrossRef Medline

Weber EU, Blais A-R, Betz NE (2002) A domain-specific risk-attitude scale: measuring risk perceptions and risk behaviors. Rochester, NY: Social Science Research Network.

Winecoff A, Clithero JA, Carter RM, Bergman SR, Wang L, Huettel SA (2013) Ventromedial prefrontal cortex encodes emotional value. J Neurosci 33:11032-11039. CrossRef Medline 